\title{
Estimating Evolutionary Volatility in a Maximum-Likelihood Framework
}

\author{
Samuel Warren Tybout \\ West Virginia University, swt0007@mix.wvu.edu
}

Follow this and additional works at: https://researchrepository.wvu.edu/etd

Part of the Evolution Commons, and the Paleontology Commons

\section{Recommended Citation}

Tybout, Samuel Warren, "Estimating Evolutionary Volatility in a Maximum-Likelihood Framework" (2020). Graduate Theses, Dissertations, and Problem Reports. 7520.

https://researchrepository.wvu.edu/etd/7520

This Thesis is protected by copyright and/or related rights. It has been brought to you by the The Research Repository @ WVU with permission from the rights-holder(s). You are free to use this Thesis in any way that is permitted by the copyright and related rights legislation that applies to your use. For other uses you must obtain permission from the rights-holder(s) directly, unless additional rights are indicated by a Creative Commons license in the record and/ or on the work itself. This Thesis has been accepted for inclusion in WVU Graduate Theses, Dissertations, and Problem Reports collection by an authorized administrator of The Research Repository @ WVU. For more information, please contact researchrepository@mail.wvu.edu. 
Estimating Evolutionary Volatility in a Maximum-Likelihood Framework

Samuel Tybout

Thesis submitted

to the Eberly College of Arts and Sciences

at West Virginia University

in partial fulfillment of the requirements for the degree of

Master of Science in

Geology

James Lamsdell, Ph.D., Chair

Brendan Anderson, Ph.D.

Craig Barrett, Ph.D.

Department of Geology and Geography

Morgantown, West Virginia

2020

Keywords: Bivalvia

Copyright 2020 Samuel Tybout 


\begin{abstract}
Estimating Evolutionary Volatility in a Maximum-Likelihood Framework
\end{abstract}

\title{
Samuel Tybout
}

Evolutionary volatility is a trait that encompasses a clade's combined capacity for origination and extinction. High volatility increases extinction risk, and declining global extinction rates are thought to be linked to declining volatility. Despite volatility's scientific importance, there is no standardized way of measuring it. This study provides a new method, derived from a stochastic birth-death model, of estimating evolutionary volatility from fossil data. Simulations indicate that the method produces accurate and precise estimates for large fossil datasets. Analysis of fossil data for five bivalve families (Lucinidae, Mytilidae, Pectinidae, Pholadomyidae, and Veneridae) indicates that diversity projections made from the estimates lack precision and do not capture important aspects of the data. However, this method of estimating volatility serves as a simple and computationally efficient null model for comparisons against more complex hypotheses. 


\section{Acknowledgments}

I would like to thank my advisor, Dr. James Lamsdell, for his guidance and patience throughout the course of this project. I would also like to thank Dr. Brendan Anderson for his helpful insights, especially regarding mollusks. I am grateful to the CRAN project and the Paleobiology Database for providing their programming language and data, respectively, free of charge. Without them, I may have had to learn how to write a grant.

I would like to thank the following people for contributing to the section of the Paleobiology

Database used in this study: A. Hendy, S. Nurnberg, U. Merkel, K. Layou, M. Uhen, M. Kosnik, F. Fursich, B. Allen, M. Krause, R. Krause, D. Hempfling, K. Bulinski, M. Clapham, D. Jablonski, M. Sommers, M. Manojlovic, J. Marcot, S. Hicks, L. Eccles, J. Sessa, S. DeLong, A. Girndt, D. Wellmanns, W. Kiessling, U. Smith, P. Wagner, M. Aberhan, M. Apel, L. Ivany, A. Tomasovych, W. Foster, M. Hethke, A. Miller, C. Visaggi, T. Schossleitner, E. Leckey, L.

Villier, P. Holroyd, C. Ferguson, E. Kowalski, P. Wall, E. Link, S. Peters, J. Alroy, M. Carrano, H. Eichiner, S. Tremblay, N. Bonuso, M. Bosnakoff, K. Hendy, D. Carlson, S. Kolbe, M. Bean, A. Kocsis, C. Powers, C. Pimiento, P. Monarrez, D. Buick, E. Orzechowski, A. McGowan, M. Nimke, E. Clites, T. Olszewski, S. Low, J. Millet, J. Wertheim, P. Harnik, E. Fara, H. O'Regan, J. Martinelli, M. Gahr, C. Peredo, D. Schramm, K. Maguire, M. Shalap, O. Will, R. Butler, and S. McMullen. 


\section{Contents}

ABSTRACT.

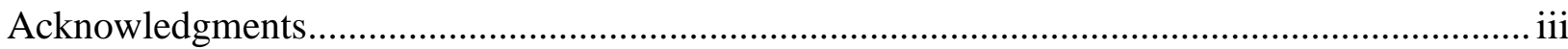

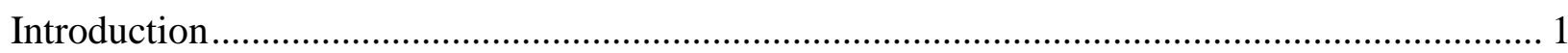

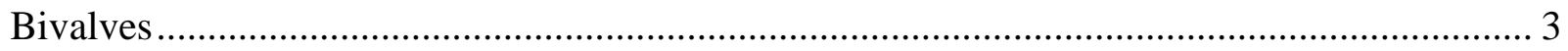

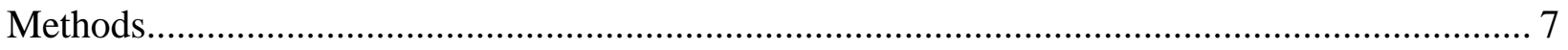

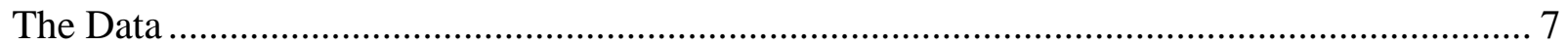

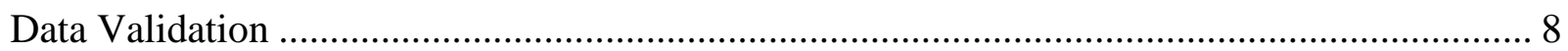

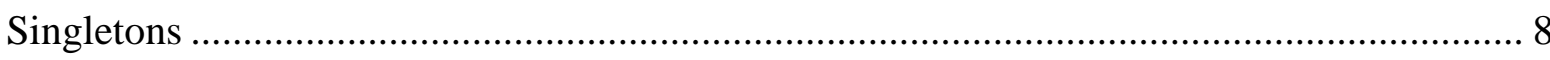

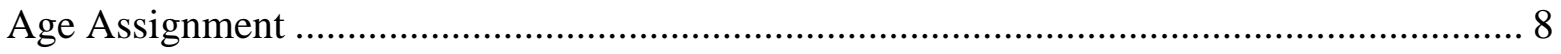

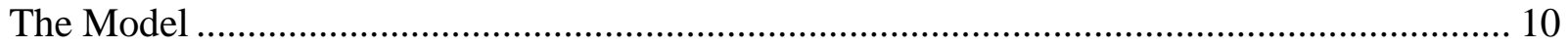

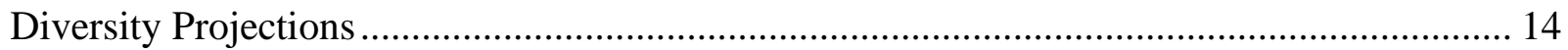

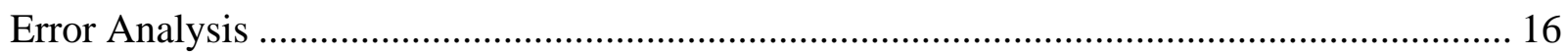

Maximum-Likelihood Estimation ..................................................................... 16

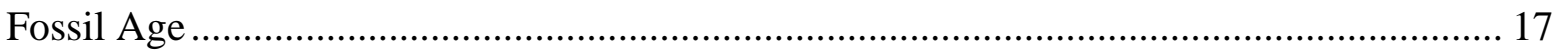

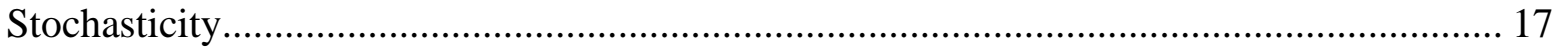

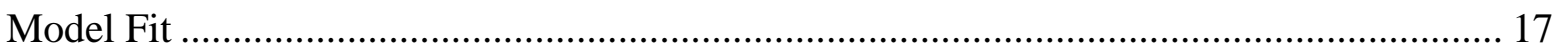

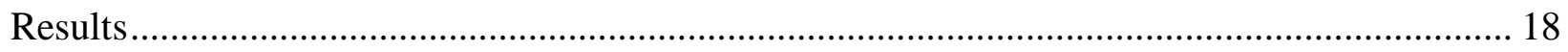

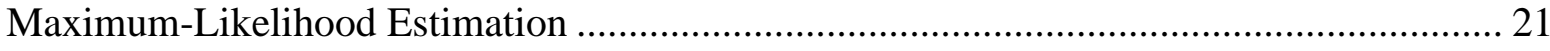

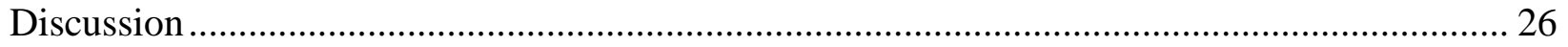


Volatility Estimates

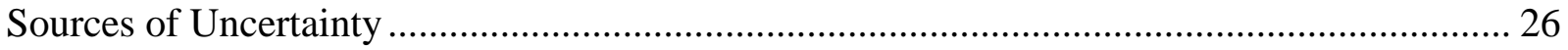

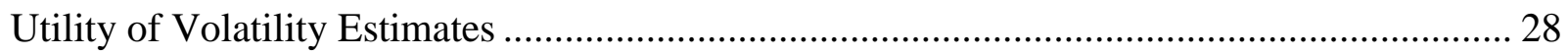

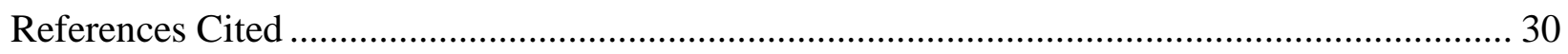

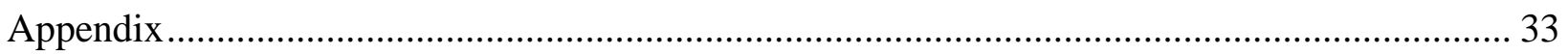

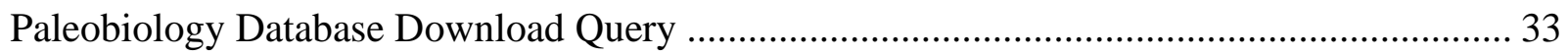

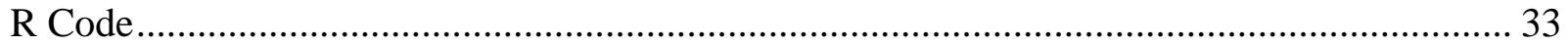




\section{Introduction}

It has been known for some time now that groups with high rates of origination also exhibit high rates of extinction (Stanley, 1990). Consequently, Gilinsky (1994) proposed a new macroevolutionary metric, volatility, that describes the combined tendency for origination and extinction (originations and extinctions per family per million years). High-volatility groups are under greater risk of extinction, despite their high rates of origination (Gilinsky, 1994). Their dramatic increases and decreases in diversity mean that they are more likely to go extinct, at which point they cannot recover.

High-volatility clades often have higher diversity than lower-volatility clades, especially early on in their history. It might therefore appear that low-volatility clades are at a greater risk of extinction if their fossil record is not examined. However, volatility theory implies that groups with high origination rates also have high extinction rates, so groups with a rapid diversification history may not be as safe as they appear.

Gilinsky and Good (1991) estimated probabilities of origination and extinction for various families in the fossil record. They developed a discrete-time model in which lineages within a family have a fixed probability of extinction and origination per time step. At each time step, each genus has a fixed probability of generating another genus and a separate probability of going extinct. Gilinsky and Good (1991) used the history of originations and extinctions within families of the fossil record to estimate the probabilities of origination and extinction for those families and found that the two probabilities are generally correlated.

Gilinsky (1994) was the first to introduce the concept of evolutionary volatility, and proposed volatility as a possible explanation for declining rates of extinction across the Phanerozoic. High- 
volatility groups are by their nature more prone to extinction. If new clades have similar volatilities to their immediate ancestors, natural selection could favor low-volatility groups in the long run. Gilinsky (1994) simulated a branching evolution process, showing that the pattern of declining simulated extinction closely matches the observed patterns of Gilinsky and Good (1991).

Volatility is thus a factor in natural selection which can only be meaningfully defined above the species level. This is an example of hierarchical selection (Vrba and Gould, 1986). A clade's volatility cannot be extrapolated from observations at the species or individual level, but volatility still constitutes an important factor in the clade's long-term extinction risk. Data from the fossil record are necessary to reliably quantify volatility and predict future evolutionary events.

Gilinsky (1994) is sometimes cited for its explanation of declining extinction (e.g. Alroy 2008; Bambach et al. 2004; Jablonski 2005), but the volatility concept is rarely discussed. Lieberman and Melott (2013) analogize the declining volatility of taxonomic groups to declining volatility in other systems, like the stock market and stars. Those systems are not branching processes and thus bear little relation to evolution, but the authors do find that Gilinsky's volatility analysis holds up with a more recent, refined fossil data set. Rominger et al. (2019) explain the unusually high frequency of large diversity shifts in the fossil record as the composite effect of gaussian fluctuations within many taxonomic groups, each with their own characteristic rate of fluctuation, or volatility. They find that families are the taxonomic level at which volatility is most conserved. 
As it stands, there is no standardized way of calculating volatility; it does not have a formal mathematical definition. Gilinsky (1994) measured the volatility $\left(V_{i}\right)$ of taxonomic orders as follows:

$$
V_{i}=\frac{1}{N} \sum_{n=1}^{N} \frac{v_{n+1}-v_{n}}{v_{n(t o t)} t_{n}}
$$

Where $v_{n}$ is the number of families that first appear in stage $\mathrm{n}, v_{n(t o t)}$ is the total extant families in stage $n, t_{n}$ is the duration of stage $n$ in millions of years and $N$ is the number of stages that the order survived. In Lieberman and Melott (2013), volatility is measured as (genus originations + genus extinctions)/(total genera). Rominger et al. (2019) use volatility as a parameter controlling the statistical distribution of diversity fluctuations within a clade:

$$
p_{k}(x \mid \beta)=\sqrt{\frac{\beta}{2 \pi}} e^{-\frac{\beta x^{2}}{2}}
$$

Here, $x$ is the size of a fluctuation, $\beta$ is the characteristic volatility of the clade, and $p_{k}(x \mid \beta)$ is the probability distribution of diversity fluctuations. This definition is distinct form other volatility concepts in that higher volatility values lead to smaller fluctuations.

In this study, volatility is calculated as the probability of origination or extinction per species per million years, using one of several simple formulas (equations 19, 20, and 24). This metric is directly related to the model of evolution used in the study and can be used to predict the probability of future diversity values, including the probability of extinction.

\section{Bivalves}

This study focuses on bivalve mollusks (hereafter called bivalves). The methods of this study require a large fossil dataset, and bivalves have one of the largest (Jablonski et al., 2003). 
Bivalves' calcareous shells fossilize well (Kidwell, 2005), and their economic importance has led to an abundance of scientific studies (e.g. Roy et al., 2000; Jablonski et al., 2003; Valentine et al., 2006). In the Paleobiology Database alone, there are over 192,000 catalogued bivalve fossil occurrences (paleobiodb.org, as of March 10, 2020).

Bivalves are a successful and widespread class within the phylum Mollusca, including wellknown animals like scallops, mussels, clams, and oysters. Most are partially sessile suspension feeders (but see Lucinidae, below), circulating water through their gills to strain out food particles (Moore et al., 1969). Bivalves protect themselves with two symmetrical shells of aragonite and/or calcite (Moore et al., 1969). Five bivalve families are studied here: the Lucinidae, Mytilidae, Pectinidae, Pholadomyidae, and Veneridae. They were selected primarily for their high diversity; Pholadomyidae was selected as a contrasting family whose diversity did not recover following the end-Cretaceous mass extinction.

The families Lucinidae, Pholadomyidae, and Veneridae are part of a large clade of burrowing clams. Lucinids, known from the Silurian, are notable for their bacterial symbiotes. They live in burrows in sulfide-rich environments, deriving nutrients from sulfate-oxidizing bacteria which live in their gills (Stanley, 2015). The Pholadomyidae, known from the Ordovician, use their elongated shells for deep burrowing (Runnegar, 1974). Unlike the other four families here, Pholadomyids do not radiate in the Cenozoic, reaching their peak diversity in the Mesozoic instead. Clams in the family Veneridae, known from the Triassic, likewise live in very deep burrows, using their ribbed shells as a sort of ratchet to drive themselves into the sediment (Morton, 1996). The Mytilidae, commonly called mussels, originated in the Devonian. They live on rocky substrates in marine and freshwater environments, attaching themselves using clusters of robust thread-like structures called byssi. Many mussels live in intertidal zones, surviving 
aerial exposure by closing their valves tightly to seal moisture within (Moore et al., 1969). The family Pectinidae, known as the scallops, are known from the Devonian as well. They live on the surface of the sediment or just beneath it. Scallops possess the somewhat alarming ability to swim by rapidly opening and closing their valves (Stanley, 2015).

Bivalves are known from the Cambrian (Taylor, 1996), and are thought to be descended from monoplacophorans (Fang and Sanchez, 2012), a rare group of single-shelled mollusks. During the Paleozoic, bivalve diversity was relatively low, but most of their extant families arose during this era (Fang and Sanchez, 2012), including the Lucinidae, Pectinidae, and Pholadomyidae. By the end of the Paleozoic, bivalves had developed all of their important ecological traits, like burrowing and byssal attachment (Stanley, 2015), and there is evidence that lucinids developed their chemosymbiosis as early as the Silurian (Morton, 1996). Seafloors in this interval were dominated by the ecologically similar brachiopods (Fraiser and Bottjer, 2007), although the difference in diversity between the two groups was probably not a result of competition (Gould and Calloway, 1980). 


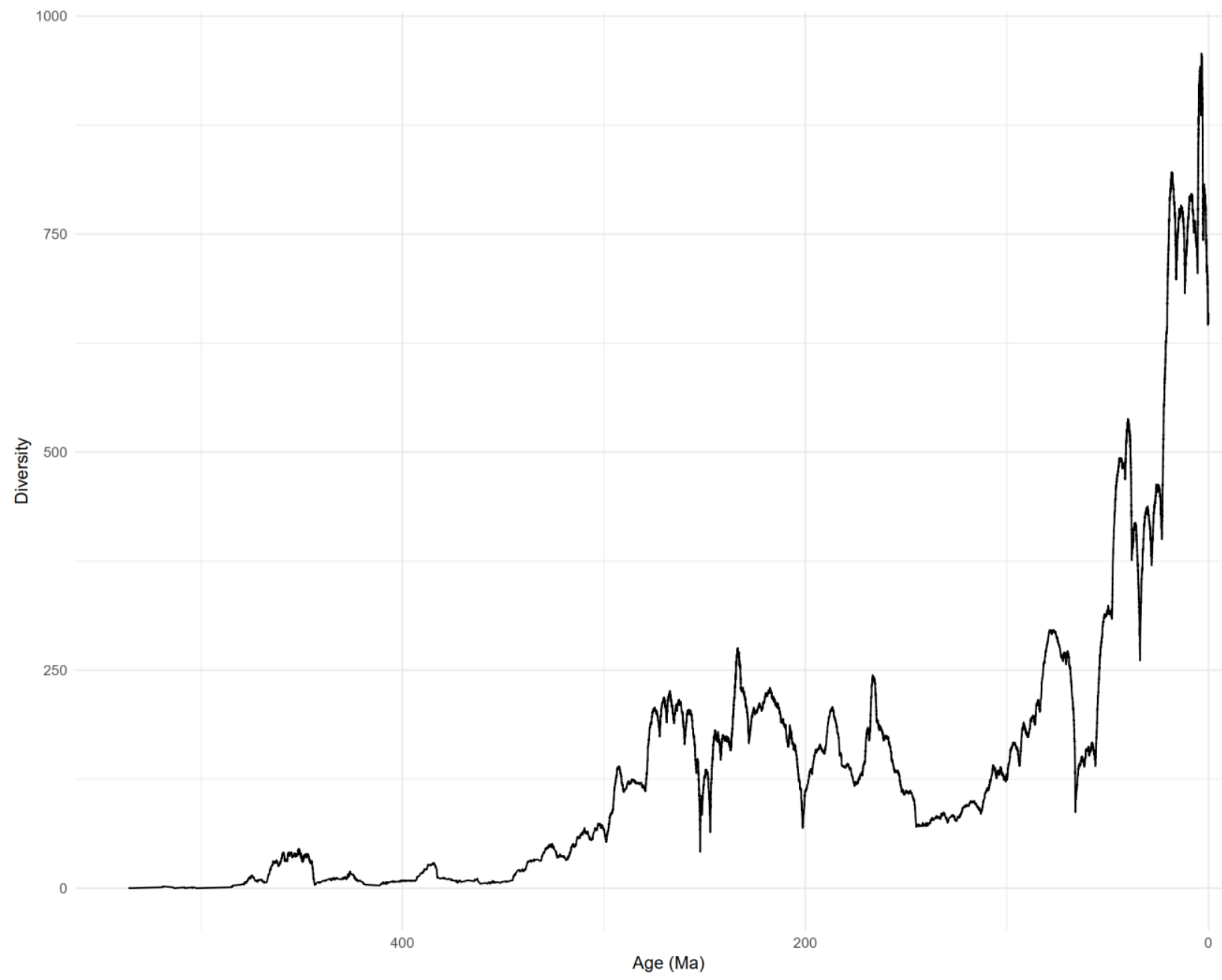

Figure 1. Species diversity of all bivalves, using occurrences in the Paleobiology Database identified at the species level. Species ranges are taken to begin at the oldest fossil in the database and end at the youngest fossil. No rarefaction was applied. Age ranges were not extended to include extant representatives.

The end-Permian extinction eliminated only about $60 \%$ of bivalve genera (Stanley, 2015), as opposed to brachiopods' 96\% extinction rate (Knoll et al., 1996). Bivalves recovered quickly from this loss and experienced an explosive radiation in the Mesozoic. Their success and diversification was part of a global ecosystem shift known as the Mesozoic Marine Revolution (Vermeij, 1977), wherein new predators such as crabs and teleost fish developed more advanced strategies for attacking shelled prey. Bivalves adapted well to this shift; the mobile Pectinidae and rapid-burrowing Veneridae diversified in this era (Stanley, 2015). The extinction at the end 
of the Cretaceous eliminated about two-thirds of bivalve genera, but not all groups were affected evenly - the Lucinidae, for example, suffered very few losses (Stanley, 2015).

Bivalve diversity continued to increase exponentially throughout the Cenozoic. Continental margins expanded as Pangea continued to split, and the geographic isolation of those environments enhanced speciation (Morton, 1996). The Lucinidae, a family which held a low standing diversity for most of its long history, radiated in the Cenozoic, likely due to the appearance of sulfide-rich habitats like seagrass beds and mangroves (Stanley, 2015). Today, bivalves enjoy high diversity in nearly all parts of the world. Of the five families studied here, only Pholadomyidae has not radiated extensively.

In this study, a new volatility metric is derived from a maximum-likelihood birth-death model. The maximum-likelihood estimation is tested against simulated data, volatilities are estimated for five bivalve families, and diversity projections are made using those estimates. This new volatility-estimation method is evaluated based on its fidelity to simulated and fossil data. The bivalve fossil record is used to compare model projections across the Cretaceous-Paleogene mass extinction.

\section{Methods}

\section{The Data}

The fossil data for this study are downloaded from the Paleobiology Database (paleobiodb.org, downloaded January 16, 2020). They consist of every bivalve fossil occurrence since the Triassic belonging to Lucinidae, Mytilidae, Pectinidae, Pholadomyidae, or Veneridae with a positive species identification—excluding any "aff.," "sp.," or “?”. Those families are chosen for their high diversity. The data include over 16,000 occurrences representing more than 2,000 species (Table 1). 


\begin{tabular}{|c|c|c|}
\hline & Occurrences & Species \\
\hline Lucinidae & 2354 & 360 \\
\hline Mytilidae & 2281 & 283 \\
\hline Pectinidae & 6002 & 751 \\
\hline Pholadomyidae & 803 & 82 \\
\hline Veneridae & 4783 & 586 \\
\hline Total & 16631 & 2062 \\
\hline
\end{tabular}

Table 1. Breakdown of dataset by occurrences and species.

\section{Data Validation}

\section{Singletons}

Of the 2062 species in the initial dataset, 704 are known only from a single occurrence in the database, as it's difficult to estimate an age range from a point occurrence. Most analyses in this study were run without singletons. Because their inclusion substantially increases volatility estimates, the volatility estimates for bivalve family volatilities are presented both with and without singletons.

\section{Age Assignment}

The continuous-time model used in this study requires that all speciation and extinction events happen at a specific point in time, rather than at some uncertain point within a time bin. However, fossils in the database are assigned an age range corresponding to a stratigraphic unit (e.g. 72.1 to $66 \mathrm{Ma}$ for the Maastrichtian). To solve this issue, each fossil occurrence in the dataset was assigned a virtual age drawn randomly from a uniform distribution within its time bin. The random age assignment has a minor effect on the analysis results, so volatility estimates were calculated for 10,000 trials, where every fossil age was randomly reassigned in each trial. 
Most studies of the fossil record assign taxa to bins rather than estimating their age numerically. Using bins is perfectly valid, but it leads to the issue of bin size. There is no objectively correct size for age bins. Too large, and most taxa will occur in only one bin. Too small, and some bins will contain few, if any, occurrences. If bins are matched to stratigraphic intervals, then the analysis must account for differing bin sizes. Furthermore, any analysis that runs computations on every bin will become more taxing as the number of bins increases, incurring a computational cost for higher stratigraphic resolution.

Point estimates of age are more likely to be found in phylogenetic studies (Forest, 2009; Bapst, 2013), where fossil data are used to assign ages to internal nodes. Minimum-node dating, where a species' time of origination is taken as the age of its oldest fossil, often runs into problems with zero-length branches which must then be corrected with some kind of transformation (Bapst and Hopkins, 2017). My study similarly uses the endpoints of a species' fossil range as its times of origination and extinction, but it does not place those dates in a phylogenetic framework.

Instead of randomly assigning ages within bins, fossil ages could be assigned to the midpoint of their containing bin (as in Nürnberg and Aberhan, 2013 or Connolly and Miller, 2001, for example). However, this would lead to a simultaneity problem—many speciation and extinction events would appear to occur at the exact same time, when in reality they were staggered. Random assignment creates a more natural-looking chain of events.

This method may be unconventional, but it has several useful effects. It naturally accounts for bin size — fossils assigned to larger bins will have a wider spread of ages then those assigned to smaller bins. It also scales well with fossil abundance-for example, species with many fossils in their terminal bin will have their average age range extend closer to the edge of that bin than 
species with only one fossil in the same bin. Furthermore, it easily handles fossils whose stratigraphic range is not constrained to a single stage or period.

Species are assumed to persist from their oldest fossil to their youngest fossil, regardless of whether any fossils were observed between those points. Age ranges were not extended beyond the observed fossil range.

\section{The Model}

I use a maximum likelihood approach to estimate the rates of origination and extinction for bivalve mollusk families. I chose bivalves for their long history, reliable preservation, and global extent (Jablonski et al., 2003). The likelihoods are estimated from a stochastic birth-death model in continuous time, formalized by Kendall (1948). The model is described below:

Each family has a characteristic speciation rate $(\lambda)$ and extinction rate $(\mu)$ which are constant through time and across all species in the group. For each species, the amount of time until the species will go extinct $\left(T_{\mu}\right)$ is randomly distributed according to an exponential distribution with rate $\mu$ :

$$
P\left(T_{\lambda}=t\right)=\mu e^{-\mu t}
$$

The amount of time until the species will experience a speciation event $\left(T_{\lambda}\right)$ is similarly distributed:

$$
P\left(T_{\lambda}=t\right)=\lambda e^{-\lambda t}
$$

These two probabilities are independent of each other. The process is memoryless, meaning that the time until the next event is identically distributed regardless of how long it has been since the previous event. The rates at which a family gains and loses species are equal to its speciation and extinction rates times its standing diversity, $\mathrm{n}$ : 


$$
\begin{gathered}
P\left(T_{\lambda}=t\right)=n \lambda e^{-n \lambda t} \\
P\left(T_{\mu}=t\right)=n \mu e^{-n \mu t}
\end{gathered}
$$

With these equations, it is possible to estimate the likelihood of any series of speciation and extinction events within a family as a function of $\lambda$ and $\mu$.

First, let us calculate the probability that, at any point in time, the next event will be a speciation. This is simply the speciation rate over the sum of all rates:

$$
P(\text { Speciation })=\frac{\lambda}{\lambda+\mu}
$$

Next, consider the probability distribution for the time until the next event (speciation or extinction) within a family. The rate for this distribution is the speciation rate plus the extinction rate times the standing diversity:

$$
P(T=t)=n(\lambda+\mu) e^{-n(\lambda+\mu) t}
$$

The probability that the next event is a speciation and that it occurs after time $t$ is the product of equations 5 and 6:

$$
P\left(\text { Speciation, } T_{\lambda}=t\right)=n \lambda e^{-n(\lambda+\mu) t}
$$

The probability that the next event is an extinction and that it occurs after time $t$ is calculated the same way:

$$
P\left(\text { Extinction, } T_{\mu}=t\right)=n \mu e^{-n(\lambda+\mu) t}
$$

Given that the data consist of a series of speciation and extinction events and the length of time between them, the likelihood of any diversity series can be expressed as 


$$
L(\text { series } \mid \lambda, \mu)=\prod_{i}^{k} P\left(\text { Speciation, } T_{\lambda}=t_{i}\right) \prod_{j}^{m} P\left(\text { Extinction, } T_{\mu}=t_{j}\right)
$$

where the first product multiplies the probabilities of all $k$ speciation events and the second multiplies the probabilities of all $m$ extinction events. We can express that more explicitly like so:

$$
L\left(\left\{t_{1}, t_{2}, \ldots, t_{k+m}\right\},\left\{n_{1}, n_{2}, \ldots, n_{k+m}\right\} \mid \lambda, \mu\right)=\prod_{i}^{k} n_{i} \lambda e^{-n_{i}(\lambda+\mu) t_{i}} \prod_{j}^{m} n_{j} \mu e^{-n_{j}(\lambda+\mu) t_{j}}
$$

To find the maximum-likelihood value of $\lambda$ and $\mu$, we find the values of those parameters that maximize the value of the above likelihood equation. We do this by taking the derivative of the likelihood equation with respect to $\lambda$ and finding the value of $\lambda$ where the derivative equals 0 ,

$$
\frac{d}{d \lambda} L(\operatorname{series} \mid \lambda, \mu)=0
$$

then doing the same for $\mu$. These equations each have a single unique solution which gives the absolute maximum likelihood. Rather than working with equation 10 directly, we will use the log-likelihood, as maximizing the logarithm of a function also maximizes the function itself. The log-likelihood can be expressed as:

$$
\ln L=\sum_{i}^{k}\left(\ln \left(n_{i} \lambda\right)-n_{i}(\mu+\lambda) t_{i}\right)+\sum_{j}^{m}\left(\ln \left(n_{j} \mu\right)-n_{j}(\mu+\lambda) t_{j}\right)
$$

We then take the derivative and set it equal to 0 ,

$$
\frac{d \ln L}{d \lambda}=\sum_{i}^{k} \frac{d}{d \lambda}\left(\ln \left(n_{i} \lambda\right)-n_{i}(\mu+\lambda) t_{i}\right)+\sum_{j}^{m} \frac{d}{d \lambda}\left(\ln \left(n_{j} \mu\right)-n_{j}(\mu+\lambda) t_{j}\right)=0
$$


Then solve for $\lambda$ :

$$
\begin{gathered}
\frac{d \ln L}{d \lambda}=\sum_{i}^{k}\left(\frac{1}{\lambda}-n_{i} t_{i}\right)+\sum_{j}^{m}\left(-n_{j} t_{j}\right)=0 \\
\frac{k}{\lambda}-\sum_{i}^{k}\left(n_{i} t_{i}\right)-\sum_{j}^{m}\left(n_{j} t_{j}\right)=0 \\
\frac{k}{\lambda}=\sum_{i}^{k}\left(n_{i} t_{i}\right)+\sum_{j}^{m}\left(n_{j} t_{j}\right)
\end{gathered}
$$

The expression on the right here is the sum of the standing diversity for each segment of the time series multiplied by the duration of that segment. We will call this $\tau$ :

$$
\begin{gathered}
\tau=\sum_{i}^{k}\left(n_{i} t_{i}\right)+\sum_{j}^{m}\left(n_{j} t_{j}\right) \\
\frac{k}{\lambda}=\tau \\
\lambda=\frac{k}{\tau}
\end{gathered}
$$

The numerator here is the total number of speciation events in the series. The maximum-likelihood estimate of $\mu$ is similar, except that the numerator is the total number of extinctions:

$$
\mu=\frac{m}{\tau}
$$

These formulas can be simplified by the assumption that $\lambda$ and $\mu$ are equal. Under this assumption, we use term $v$ for volatility, which is equal to the sum of $\lambda$ and $\mu$. 


$$
\begin{gathered}
\lambda=\mu \\
v=\lambda+\mu=2 \lambda=2 \mu \\
P(\text { Event })=n v e^{-n v t}
\end{gathered}
$$

The maximum-likelihood value of $v$ can be calculated in the same way as $\lambda$ and $\mu$ :

$$
v=\frac{k+m}{\tau}
$$

All likelihood equations after Equation 11 are technically invalid if any $n_{i}=0$, meaning that the diversity of the clade drops to 0 and then recovers. This makes logical sense, as species shouldn't appear out of nowhere. However, it can be generally assumed that any 0 s in the middle of series are the result of incomplete preservation, not biological miracles. Equations 19, 20, and 24 can still be used to find maximum-likelihood parameters for such series, even though the likelihood itself is undefined.

\section{Diversity Projections}

The same stochastic model that is used in the maximum likelihood equations can also be used to calculate the probability of a clade having a particular diversity at a point in its future. The equations in this section are modified from the work of Raup (1985).

The probability that a clade will have a positive diversity $n$ after time $t$ given initial diversity $n_{0}$ is given by

$$
P_{n, t}=\sum_{j=0}^{\min \left(n_{0}, n\right)}\left(\begin{array}{c}
n_{0} \\
j
\end{array}\right)\left(\begin{array}{c}
n_{0}+n-j-1 \\
n_{0}-1
\end{array}\right) \alpha^{n_{0}-j} \beta^{n-j}(1-\alpha-\beta)^{j}
$$

The $\alpha$ in this equation is the probability that the clade will become extinct before time $t$ : 


$$
\alpha=\frac{\mu\left(e^{(\lambda-\mu) t}\right)-1}{\lambda e^{(\lambda-\mu) t}-\mu}
$$

$\beta$ is defined with respect to $\alpha$ :

$$
\beta=\alpha\left(\frac{\lambda}{\mu}\right)
$$

With the assumption that $\lambda=\mu$, the probability of having diversity $n$ after time $t$ can be defined in terms of volatility:

$$
P_{n, t}=\left(\frac{v t}{2+v t}\right)^{\left(n_{0}+n\right)} \cdot \sum_{j=1}^{\min \left(n_{0}, n\right)}\left(\begin{array}{c}
n_{0} \\
j
\end{array}\right)\left(\begin{array}{c}
n-1 \\
j-1
\end{array}\right)\left(\frac{v}{2} t\right)^{-2 j}
$$

The probability of extinction in this case is somewhat simpler:

$$
P_{0, t}=\left(\frac{v t}{2+v t}\right)^{n_{0}}
$$

Note that the probability of extinction increases as volatility increases, approaching 1 as $v$ approaches infinity.

The probability equations for different fields of parameter space are summarized in Table 2.

\begin{tabular}{|c|c|c|}
\hline & $P_{n, t}$ & $P_{0, t}$ \\
\hline
\end{tabular}




\begin{tabular}{|c|c|c|}
\hline$\lambda=\mu=\frac{v}{2}$ & $\left(\frac{v t}{2+v t}\right)^{\left(n_{0}+n\right)} \cdot \sum_{j=1}^{\min \left(n_{0}, n\right)}\left(\begin{array}{c}n_{0} \\
j\end{array}\right)\left(\begin{array}{c}n-1 \\
j-1\end{array}\right)\left(\frac{v}{2} t\right)^{-2 j}$ & $\left(\frac{v t}{2+v t}\right)^{n_{0}}$ \\
\hline$\lambda \neq \mu$ & $\sum_{j=0}^{\min \left(n_{0}, n\right)}\left(\begin{array}{c}n_{0} \\
j\end{array}\right)\left(\begin{array}{c}n_{0}+n-j-1 \\
n_{0}-1\end{array}\right) \alpha^{n_{0}-j} \beta^{n-j}(1-\alpha$ & $\frac{\mu\left(e^{(\lambda-\mu) t}\right)-1}{\lambda e^{(\lambda-\mu) t}-\mu}$ \\
$-\beta)^{j}$ &
\end{tabular}

Table 2. Probability of having diversity $n\left(P_{n, t}\right)$ or $0\left(P_{0, t}\right)$ after $t$ time has elapsed, given initial diversity $n_{0}$. Definitions for $\alpha$ and $\beta$ can be found in equations 26 and 27.

To project a family's future diversity, I construct pseudo-confidence intervals from these probability equations. For any point in the future, I found the most probable diversity given the family's present diversity and its estimated volatility. Then, I expand the range of possible diversity values until their total probability is at least 0.95 .

A similar approach is used to analyze the significance of the end-Cretaceous extinction under the birth-death model. The data are split into two groups: fossils older than $70 \mathrm{Ma}$ (the estimation dataset), and fossils younger than $70 \mathrm{Ma}$ (the test dataset). The older fossils are used to estimate the volatility of a family. Diversity is projected starting from $70 \mathrm{Ma}$ and the projections are compared to the real diversity history known from the younger fossils.

\section{Error Analysis}

The estimates and predictions in this study have four principal sources of uncertainty: maximumlikelihood parameter estimation, fossil age assignment, stochasticity, and model fit. Each source is quantified to some extent in the analysis.

\section{Maximum-Likelihood Estimation}

One of the major weaknesses of a maximum likelihood approach is that the parameters returned are simply point estimates; there is no statistical confidence associated with them. To analyze the 
accuracy and precision of the estimates produced by equations $19-24$, I ran 1,000 simulations of the birth-death process described by the model under a range of volatility values. I then compared the $v$ put into the simulations to the $v$ returned by the maximum likelihood formula.

From those results, I fit an equation which describes the error rate in the estimates as a function of the estimated volatility and size of the dataset. The equation was applied to all volatility estimates in the analysis as a measure of uncertainty.

\section{Fossil Age}

Random assignment of virtual fossil ages affects the sequence of speciation and extinction events in the dataset and the time between them. For each bivalve family, volatility was estimated 1,000 times for different random age assignments. The resultant distribution of estimates was combined with the estimated error from maximum-likelihood estimation (above) to give an overall probability distribution for the volatility of each family.

\section{Stochasticity}

Even if the volatility estimate is perfectly accurate and reality behaves exactly as in the model, diversity projections have uncertainty derived from the stochastic nature of the model. This projection uncertainty is quantified by Raup's (1985) equations. The projections made here generally assume $\lambda=\mu$, so the relevant formula is Equation 28 of Raup (1985).

\section{Model Fit}

The birth-death model described here is obviously a major simplification of the real process of evolution, but the degree to which its simplifications are acceptable is difficult to quantify. The assumption that $\lambda=\mu$ is evaluated using the Akaike Information Criterion (AIC: Akaike, 1974). One can always increase the likelihood of an estimate by introducing more parameters into their 
model, so it is necessary to determine which parameters contribute enough to the fit of the model to justify the added complexity. The AIC weighs the likelihoods given by different maximumlikelihood estimators against the number of parameters they require. In this study, the AIC is used to compare the model where $\lambda=\mu=\frac{v}{2}$ (1 parameter) to one where $\lambda \neq \mu$ (2 parameters). In this case, series with gaps $\left(n_{i}=0\right)$ cannot be used because the AIC involves calculating likelihood directly. Consequently, the fossil record for each family was restricted to a time range where no gaps occurred: 170 to $70 \mathrm{Ma}$ for Pholadomyidae and 100 to $0 \mathrm{Ma}$ for all others.

The back-projections, in which the projections generated from the first half of a family's history are compared to the actual second half of its history, also give some information about model fit. If the model is a perfect fit, one would expect the actual history to fall within the projected range most of the time (95\% of the time for a $95 \%$ confidence projection). If deviations from the projections are more frequent, that implies that the model does not account for some important evolutionary processes.

\section{Results}

The volatility estimates for the five families fell between 0.1 and 0.4 events per species per million years (Table 3, Figure 2). The singletons in this dataset have a huge effect on volatility estimates, in some cases almost doubling the value. However, in no case do they change the rank order of the estimates.

\begin{tabular}{|l|r|r|}
\hline & With Singletons & Without Singletons \\
\hline Mytilidae & 0.235677 & 0.128326 \\
\hline Lucinidae & 0.356927 & 0.217693 \\
\hline Veneridae & 0.297688 & 0.199155 \\
\hline
\end{tabular}




\begin{tabular}{|l|l|l|}
\hline Pectinidae & 0.249240 & 0.169902 \\
\hline Pholadomyidae & 0.245716 & 0.158214 \\
\hline
\end{tabular}

Table 3. Maximum-likelihood volatility estimates for bivalve families (events per species per million years), with and without singleton species.

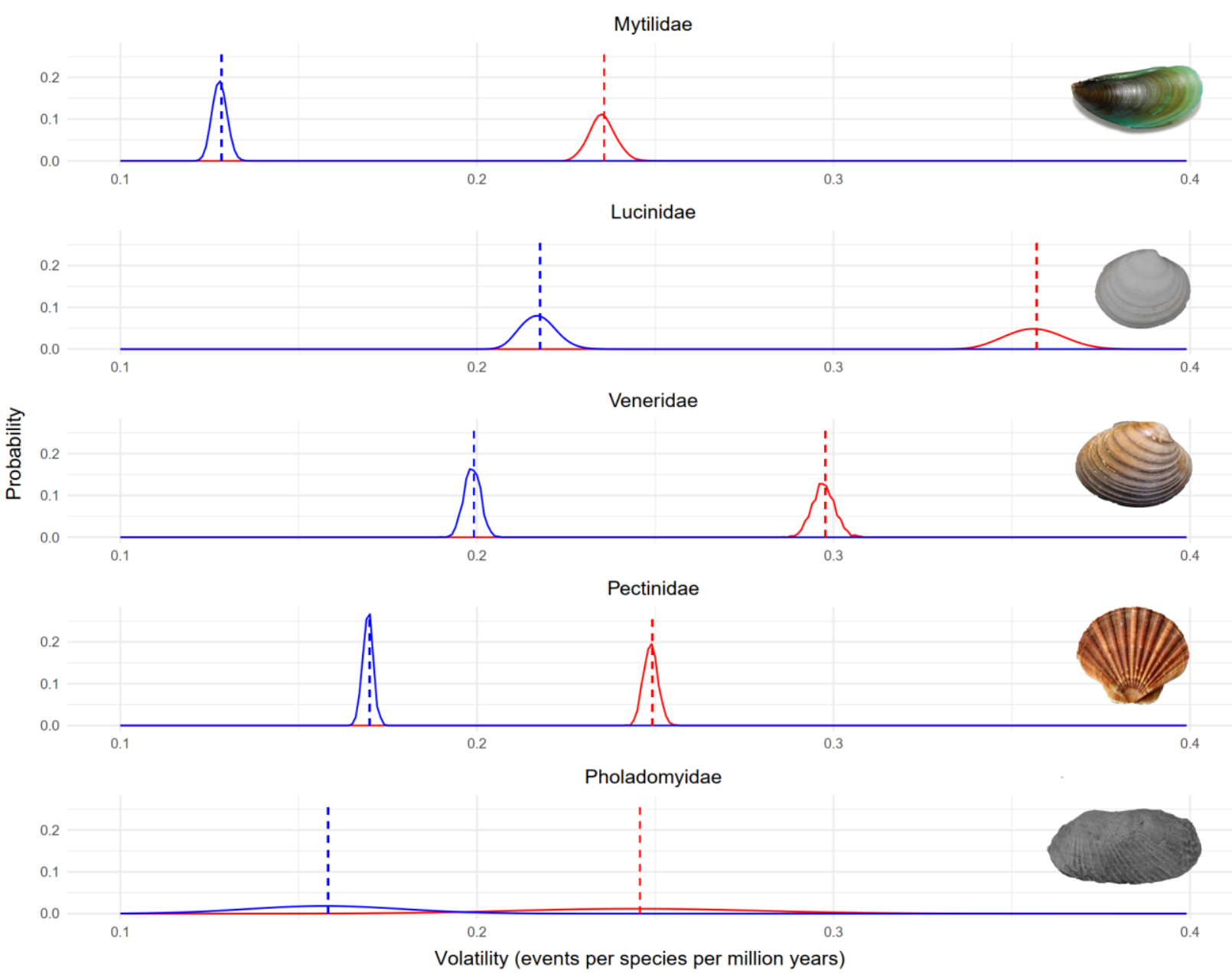

Figure 2. Probability distributions of the volatility estimates for the five bivalve families. Red: with singletons. Blue: without singletons. Dashed lines: mean.

Projections based on the first half of bivalves' fossil records did not consistently predict the second half of their records (figure 3). The end-Cretaceous mass extinction dropped diversity below the 95\% confidence interval for all but Lucinidae, and the Cenozoic diversification brought diversity above the confidence interval for all but Mytilidae and Pholadomyidae. 
The most successful projections are for Pholadomyidae and Mytildiae, where the clades' relatively modest Cenozoic diversity falls within the predicted interval.
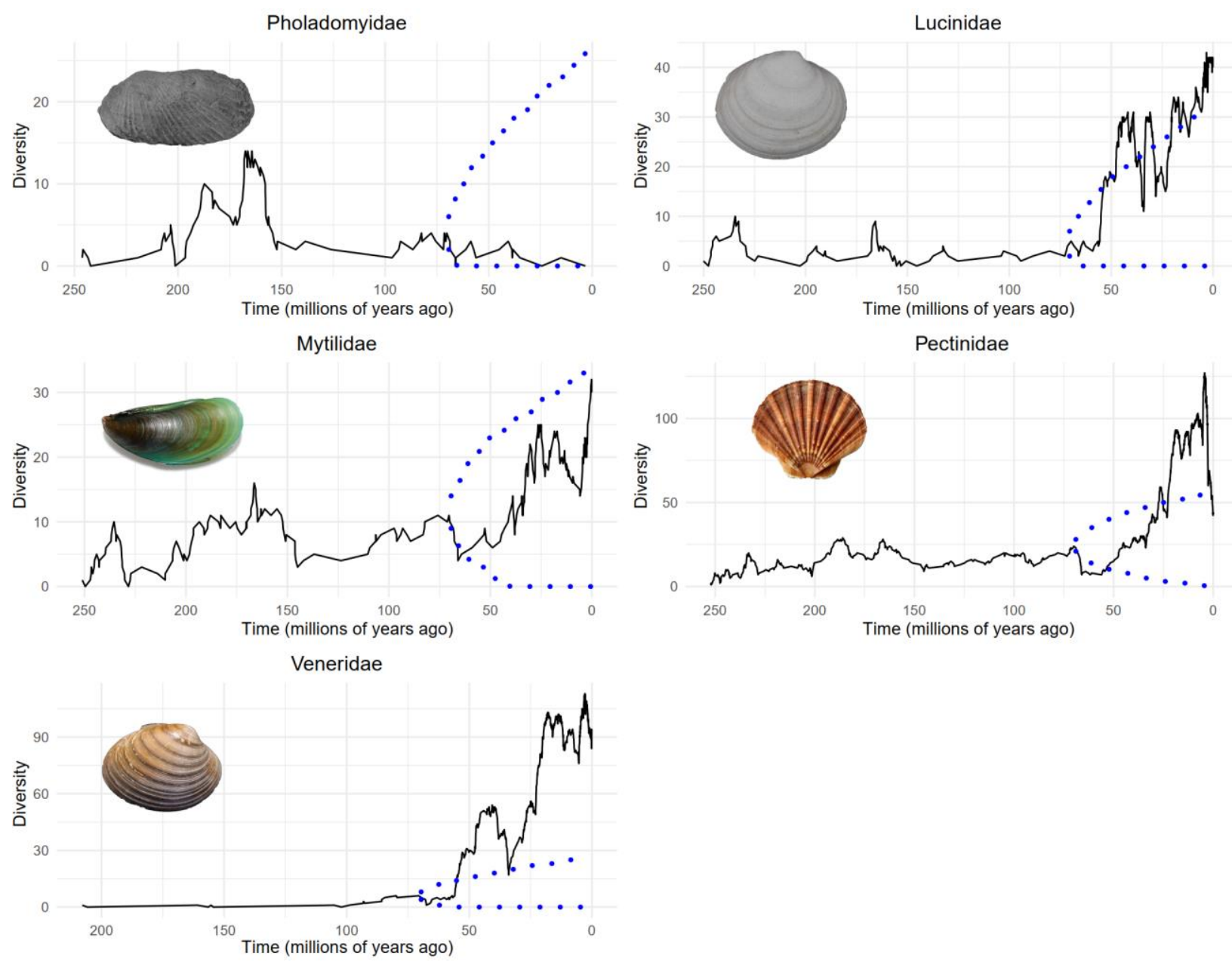

Figure 3. 95\% confidence projections (dotted blue envelope) of Cenozoic species diversity for bivalve families, given their Mesozoic fossil record. Black line shows actual diversity. Species ranges are taken to begin at the oldest fossil in the database and end at the youngest fossil. No rarefaction was applied. Age ranges were not extended to include extant representatives.

Projections of future diversity in the next 50 million years are broad for the four extant families (figure 4). The confidence intervals have ranges of 50 to 100 species. The projections indicate that none of these families is likely to become extinct in this time interval, but beyond that, the precision of the projections is low. 

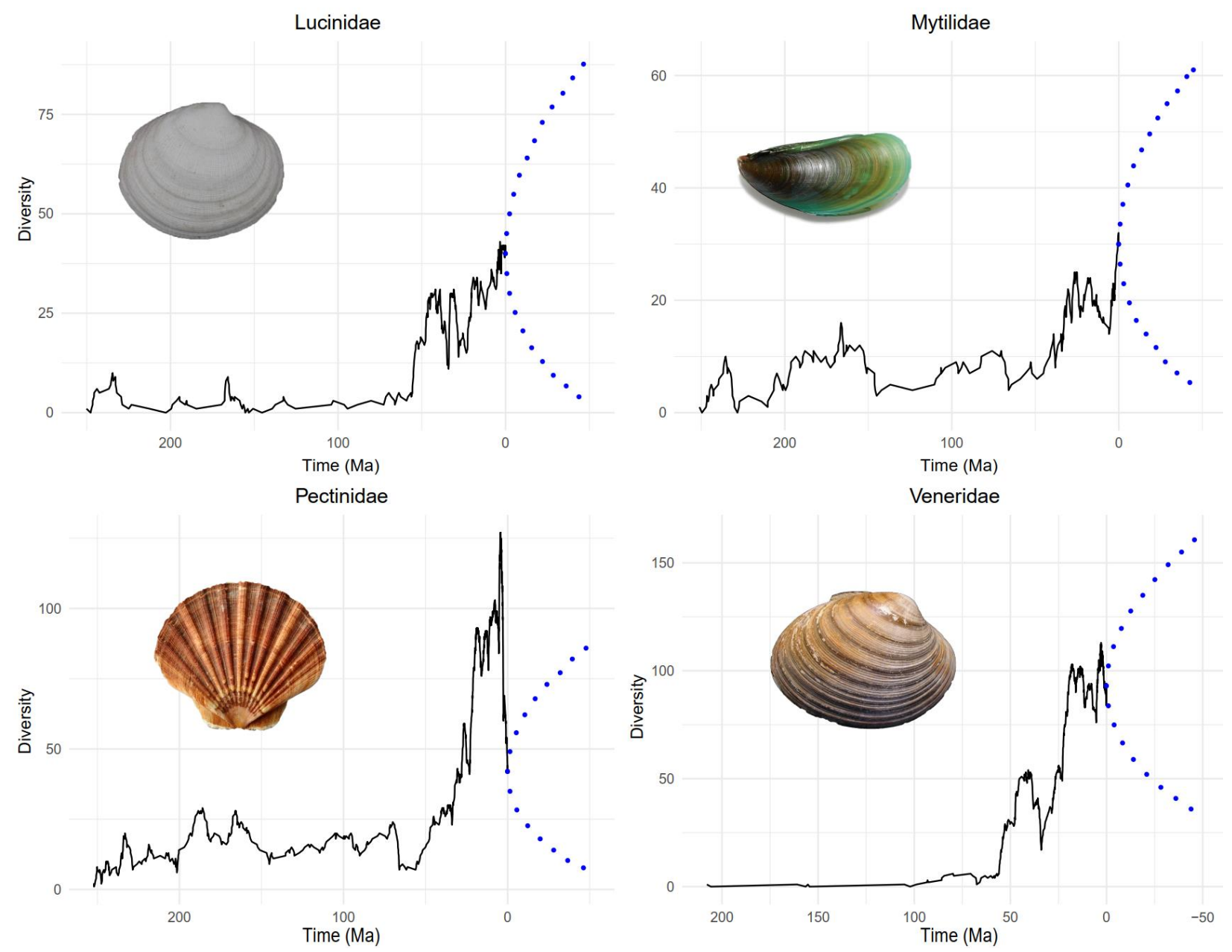

Figure 4. 95\% confidence projections of future species diversity (dotted blue envelope) for bivalve families, given fossil record (black line). Pholadomyidae is excluded here as the Paleobiology Database lacks recent fossil occurrences for that clade. Species ranges are calculated as in Figure 3.

\section{Maximum-Likelihood Estimation}

In simulations, the maximum-likelihood formula (equation 17) produces accurate and precise estimates of volatility for any dataset with enough taxon-years $(\tau)$. For the simulated datasets with $\tau>200$, the mean volatility estimate was accurate (figure 6), and the standard deviation of the estimates decreased exponentially with $\tau$ (figure 5). The following equation, fit to the simulation results, describes the standard deviation of the volatility estimates as a function of the true volatility $(v)$ and $\tau$ : 


$$
\sigma=0.51 e^{-0.002 \tau} v
$$

Four of the five families studied here have $\tau>2000$, making the error less than $0.01 v$. For Pholadomyidae $(\tau \approx 650)$, the error is about $0.14 v$.

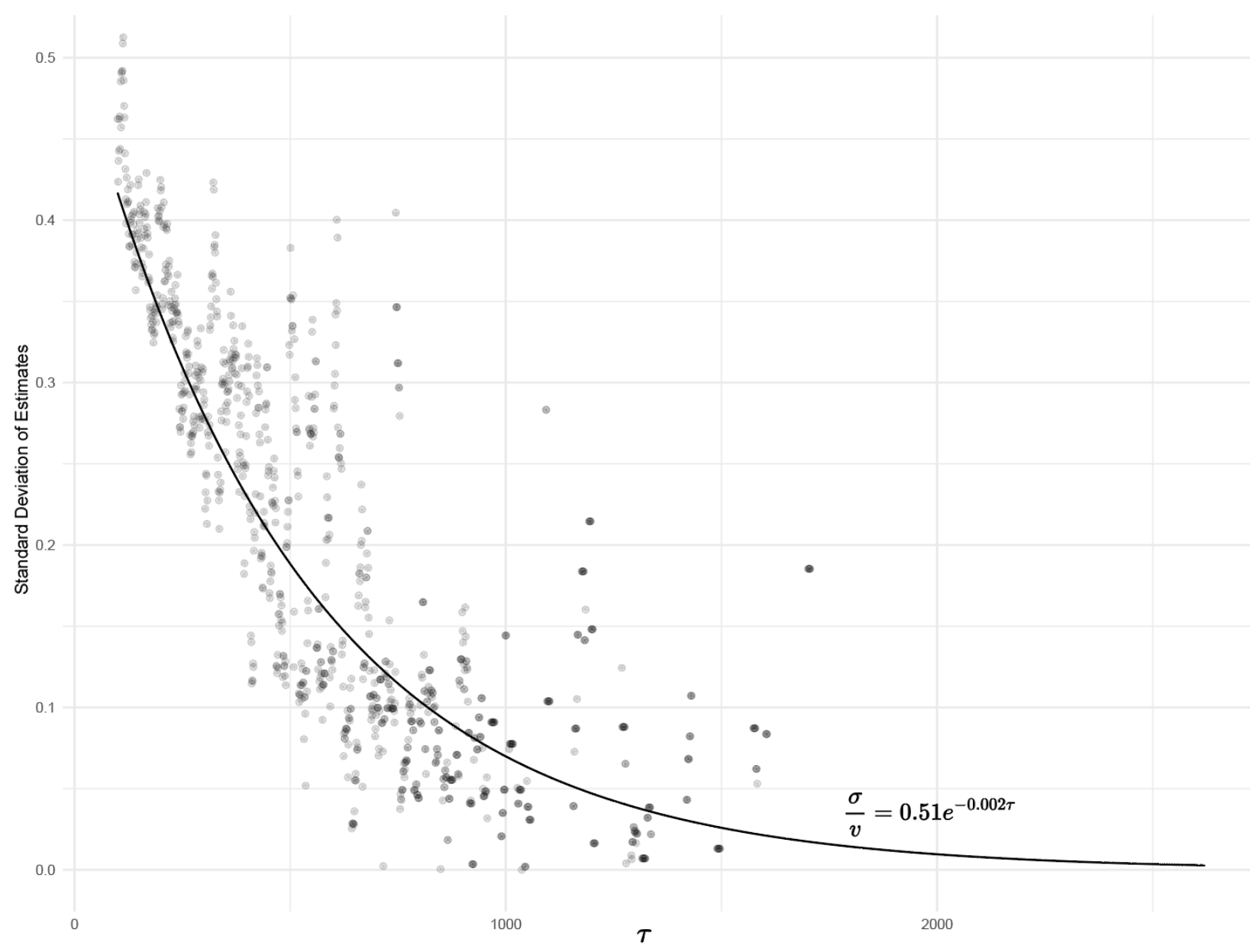

Figure 5. Standard deviation of volatility estimates as a function of $\tau$. Vertical axis is the standard deviation of the estimates divided by the simulated volatility. Equation describes the line of best fit. 


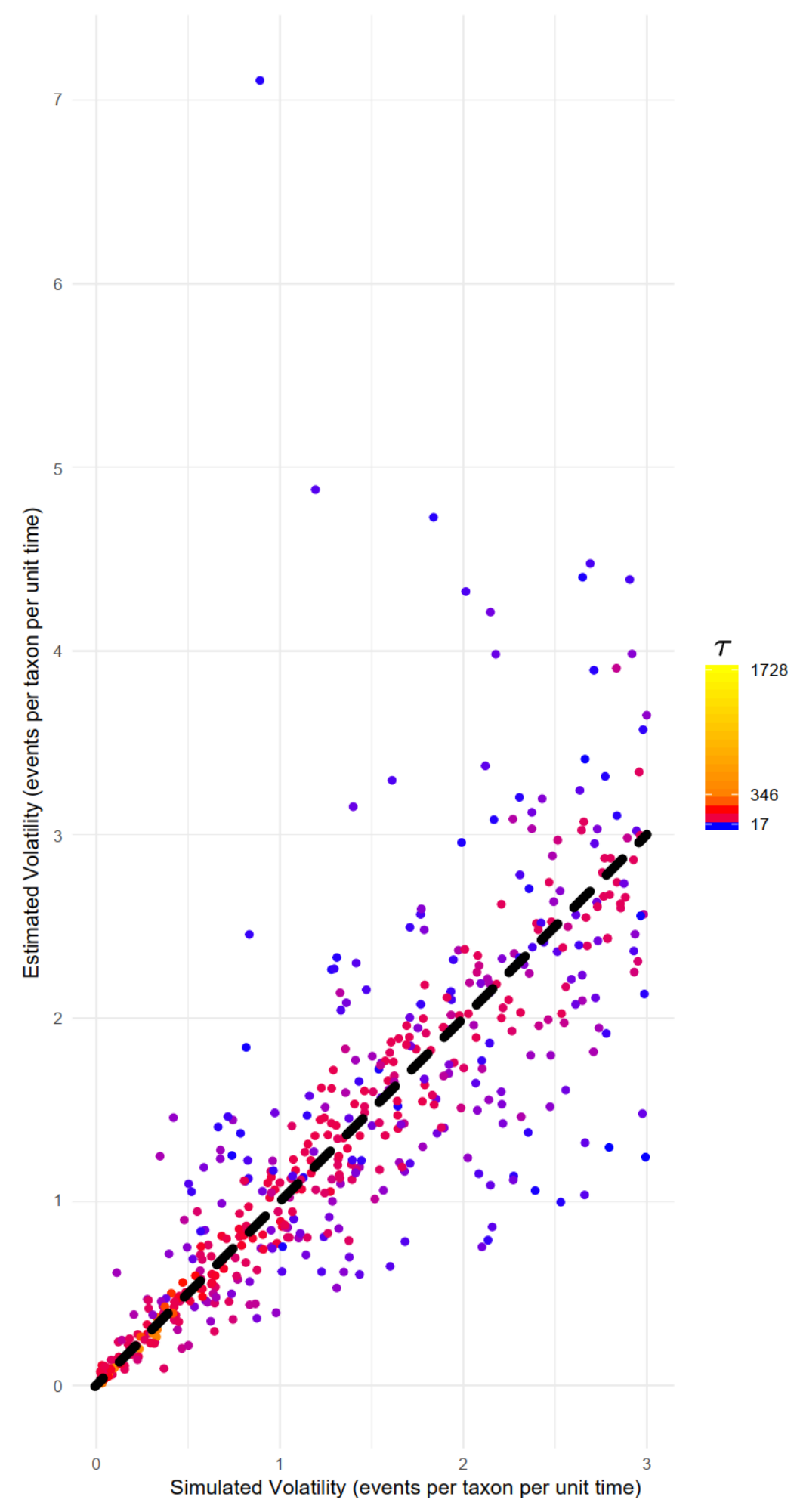

Figure 6. Volatility estimates from simulated datasets. Color corresponds to $\tau$ value for that dataset (see equation 17). 
Within-bin randomization of fossil ages has a relatively small impact on volatility estimates. The distribution of volatility estimates across random variates is symmetrical and apparently normal (figures 7 and 8). The standard deviation of the estimates is approximately 0.002 for Mytilidae and 0.004 for Lucinidae - about $1 \%$ of the mean in both cases.

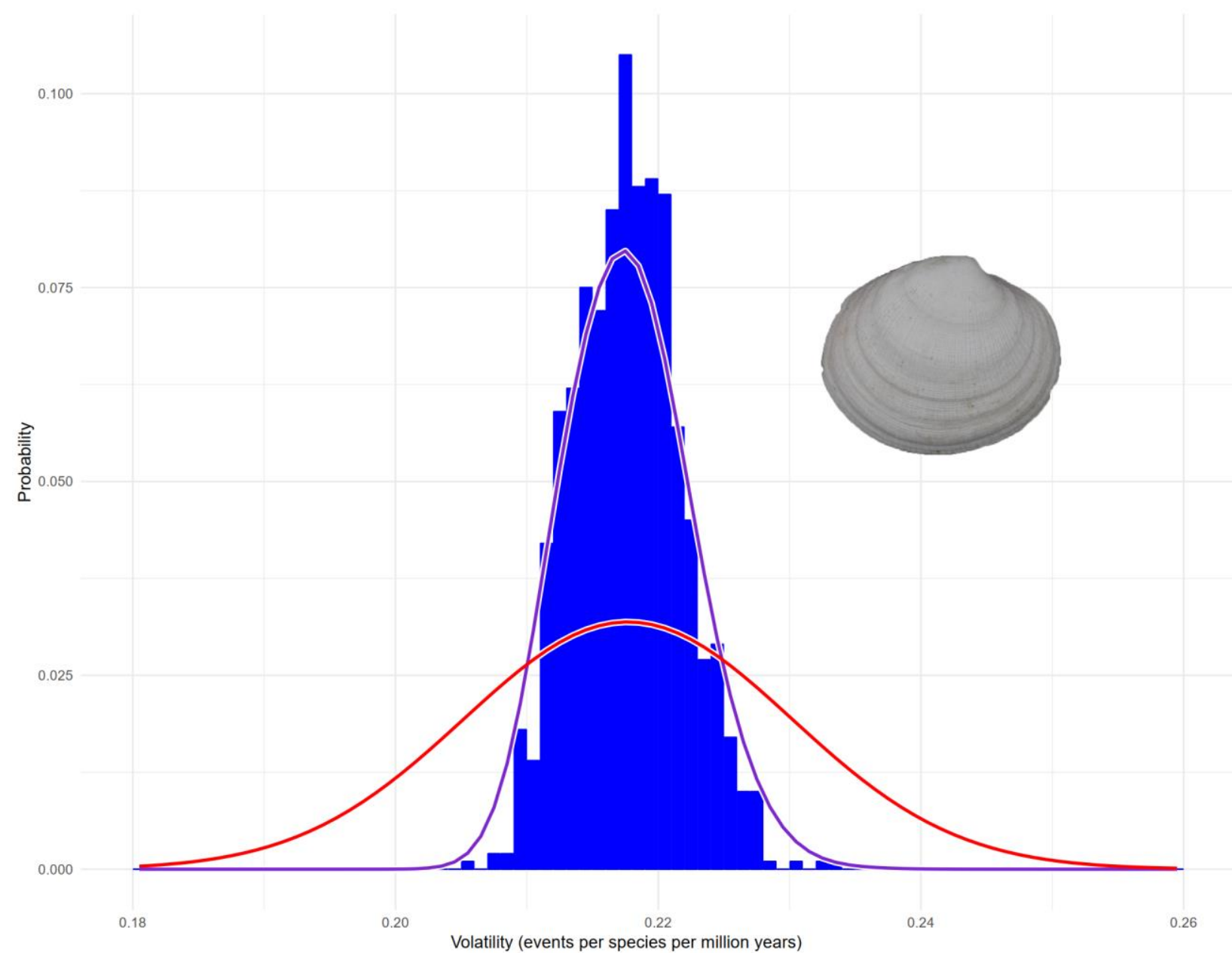

Figure 7. Distribution of volatility estimates for Lucinidae, accounting for various sources of error. Blue histogram: estimate distribution across 10,000 random fossil age assignments. Red curve: distribution accounting for error in maximum likelihood estimation. Purple curve: distribution accounting for error in both age assignment and maximum likelihood estimation. 


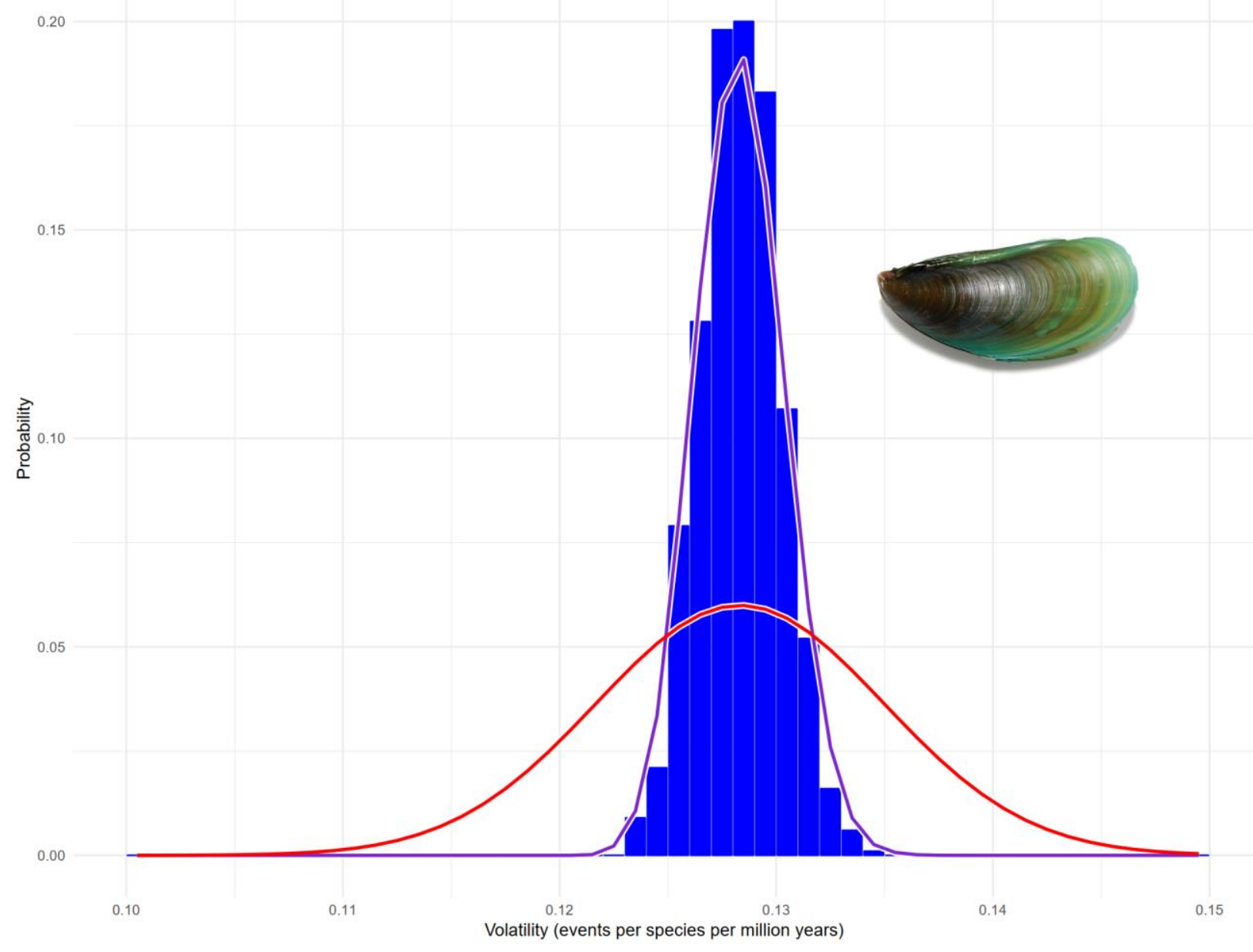

Figure 8. Distribution of volatility estimates for Mytilidae, as in figure 5.

The AIC tests found that $\lambda=\mu=\frac{v}{2}$ was preferred over $\lambda \neq \mu$ for all five bivalve families (Table 4). This indicates that speciation rate is not significantly higher than extinction rate for these bivalves.

\begin{tabular}{|c|c|c|c|}
\hline Family & $\begin{array}{c}\text { Log } \\
\text { Likelihood }\end{array}$ & \multicolumn{1}{|c|}{ AIC } & Preferred Model \\
\hline Lucinidae & 36.87047 & -71.7409 & $\lambda=\mu=\frac{v}{2}$ \\
\hline Mytilidae & 151.1678 & -300.336 & $\lambda=\mu=\frac{v}{2}$ \\
\hline Pectinidae & -585.58 & 1173.16 & $\lambda=\mu=\frac{v}{2}$ \\
\hline
\end{tabular}




\begin{tabular}{|c|l|l|l|}
\hline Pholadomyidae & 95.5083 & -189.017 & $\lambda=\mu=\frac{v}{2}$ \\
\hline Veneridae & -525.93 & 1053.859 & $\lambda=\mu=\frac{v}{2}$ \\
\hline
\end{tabular}

Table 4. Results of Akaike Information Criterion (AIC) comparisons of two alternative models: $\lambda=\mu=\frac{v}{2}$ versus $\lambda \neq \mu$.

\section{Discussion}

\section{Volatility Estimates}

The maximum-likelihood volatility estimates look reasonable, given the history of the families. Lucinidae and Veneridae's high volatility can be attributed to their sudden rise in the Cenozoic from a previously low diversity. Notably, lucinids are the family least affected by the endCretaceous extinction, making their high volatility purely a result of background extinction and speciation. The volatility of Mytilidae is found to be low due to its relatively low diversity fluctuations despite a high standing diversity throughout its history.

Volatility estimates for Pholadomyidae have much lower certainty due primarily to their smaller $\tau$ value, which is less than half that of the other families. All differences between with-singleton and without-singleton estimates are proportional to the number of singletons belonging to that family in the dataset.

\section{Sources of Uncertainty}

The maximum-likelihood volatility estimator developed in this study appears to be reliable for any clade with even a moderate amount of fossil data. This method should be reasonably accurate for any clade with more than about 500 species which persisted for at least 1 million years each. For clades with a much richer fossil record, it should be possible to generate 
parameter estimates for many subdivisions of the clade's fossil history, enabling the study of parameter change through time.

In comparison to the error associated with maximum-likelihood estimation, the uncertainty associated with random fossil age assignment is relatively small. Still, it is large enough that conducting the analysis for many independent age variates is worthwhile. It is worth noting that this method does not introduce a new source of uncertainty into the data; rather, it captures an extant uncertainty which is not always considered. Within-bin age uncertainty is impactful for any study where a difference of a few million years on every fossil can have a noticeable effect on the results.

The projection tests against fossil data show that the model's predictions are not accurate outside of background speciation and extinction conditions. This makes the projections unsuitable for periods of earth history where there is a major disturbance to normal evolutionary patterns, such as the present biodiversity crisis (Wake and Vredenburg, 2008).

The failure of the projections to encapsulate bivalves' Cenozoic fossil history highlights the disparities between a simple birth-death model and the actual evolutionary dynamics at play. The simplest explanation for the discrepancy is that the volatility of bivalve families is not constant through time. The Cenozoic radiation of bivalves, and the failure of Mesozoic data to account for it, indicates that their volatility increased. This would run counter to the general observations of Gilinsky (1994) and Lieberman and Melott (2013), but it should be noted that this study specifically selected high-diversity, extant families, which would be less likely to follow that trend. The model also does not account for any potential diversity-dependent dynamics, although the exponential growth of bivalve diversity does not appear to be limited by any taxonomic carrying capacity. 
The AIC tests favored $\lambda=\mu$ over $\lambda \neq \mu$, indicating that speciation rates are not significantly higher than extinction rates for these bivalves. That equality may break down if the data are analyzed in a more piecewise fashion, especially close to mass extinction events.

Gilinsky (1994) predicted that volatility should be declining across the Phanerozoic, but bivalves appear to show the opposite pattern, with higher volatility in the Cenozoic than in the Mesozoic. If the end-Cretaceous extinction operated under a different selective regime than background processes (Jablonski, 1986), it could have preferentially removed low-volatility groups. It has been suggested that clades with high diversity in the Cenozoic found success thanks to mass extinction resistance (Knope et al., 2020), which could explain the present diversity of bivalves.

\section{Utility of Volatility Estimates}

Ultimately, a stochastic birth-death process is a null model. Its simplicity is intentional, and its purpose is to serve as a point of comparison for more complex hypotheses, like diversitydependence or bursts of diversification. Maximum-likelihood volatility serves as an easy means of connecting fossil data to that null model. The analytical formula makes estimating $v$ exceptionally fast, eliminating the need for a computationally intensive search of parameter space and repeated likelihood re-evaluation, as is necessary with many model parameters (like those in Rominger et al., 2019, for example).

This method's simplicity makes it easy to expand upon it. Change in volatility over time could be analyzed simply by separating the dataset into segments, with the caveat that smaller subsets of the data will give less precise volatility estimates. Perhaps the most promising direction to proceed from this study would be to incorporate a phylogenetic element. If it could be shown 
that related clades have more similar volatilities, that would support Gilinsky (1994)'s hypothetical cause of declining extinction rates. 


\section{References Cited}

Akaike, H., 1974, A new look at the statistical model identification: IEEE Transactions on Automatic Control, v. 19, p. 716-723, doi:10.1109/TAC.1974.1100705.

Alroy, J., 2008, Dynamics of origination and extinction in the marine fossil record: Proceedings of the National Academy of Sciences, doi:10.1073/pnas.0802597105.

Bambach, R.K., Knoll, A.H., and Wang, S.C., 2004, Origination, extinction, and mass depletions of marine diversity: Paleobiology, v. 30, p. 522-542, doi:10.1666.

Bapst, D.W., 2013, A stochastic rate-calibrated method for time-scaling phylogenies of fossil taxa: Methods in Ecology and Evolution, v. 4, p. 724-733, doi:10.1111/2041-210X.12081.

Bapst, D.W., and Hopkins, M.J., 2017, Comparing cal3 and other a posteriori time-scaling approaches in a case study with the pterocephaliid trilobites: Paleobiology, v. 43, p. 49-67, doi:10.1017/pab.2016.34.

Connolly, S.R., and Miller, A.I., 2001, Joint estimation of sampling and turnover rates from fossil databases: capture-mark-recapture methods revisited: Paleobiology, v. 27, p. 751-767, doi:10.1666/0094- 8373(2001)027.

Fang, Z., and Sanchez, T.M., 2012, Origin and early evolution of the Bivalvia, in Selden, P.A. ed., Treatise Online no. 43: Part N, Revised, Volume 1, Chapter 16, Paleontological Institute, The University of Kansas, p. 1-21, https://journals.ku.edu/treatiseonline/article/view/4275.

Forest, F., 2009, Calibrating the Tree of Life: fossils, molecules and evolutionary timescales: Annals of Botany, v. 104, p. 789-794, doi:10.1093/aob/mcp192.

Fraiser, M.L., and Bottjer, D.J., 2007, When bivalves took over the world: Paleobiology, v. 33, p. 397413, doi:10.1017/S0094837300026361.

Gilinsky, N.L., 1994, Volatility and the Phanerozoic decline of background extinction intensity: Paleobiology, v. 20, p. 445-458, doi:10.1017/S0094837300012926.

Gilinsky, N.L., and Good, I.J., 1991, Probabilities of Origination, Persistence, and Extinction of Families of Marine Invertebrate Life: Paleobiology, v. 17, p. 145-166.

Gould, S.J., and Calloway, C.B., 1980, Clams and Brachiopods-Ships that Pass in the Night: Paleobiology, v. 6, p. 383-396.

Jablonski, D., 1986, Background and Mass Extinctions: The Alternation of Macroevolutionary Regimes: Science, v. 231, p. 129-133.

Jablonski, D., 2005, Mass extinctions and macroevolution: Paleobiology, v. 31, p. 192-210, doi:10.1666.

Jablonski, D., Roy, K., Valentine, J.W., Price, R.M., and Anderson, P.S., 2003, The impact of the pull of the recent on the history of marine diversity: Science; Washington, v. 300, p. 1133-5.

Kendall, D.G., 1948, On the Generalized "Birth-and-Death" Process: The Annals of Mathematical Statistics, v. 19, p. 1-15, doi:10.1214/aoms/1177730285. 
Kidwell, S.M., 2005, Shell Composition Has No Net Impact on Large-Scale Evolutionary Patterns in Mollusks: Science, v. 307, p. 914-917, doi:10.1126/science.1106654.

Knoll, A.H., Bambach, R.K., Canfield, D.E., and Grotzinger, J.P., 1996, Comparative Earth History and Late Permian Mass Extinction: Science, v. 273, p. 452-457, doi:10.1126/science.273.5274.452.

Knope, M.L., Bush, A.M., Frishkoff, L.O., Heim, N.A., and Payne, J.L., 2020, Ecologically diverse clades dominate the oceans via extinction resistance: Science, v. 367, p. 1035-1038, doi:10.1126/science.aax6398.

Lieberman, B.S., and Melott, A.L., 2013, Declining volatility, a general property of disparate systems: from fossils, to stocks, to the stars (C. Congreve, Ed.): Palaeontology, v. 56, p. 1297-1304, doi:10.1111/pala.12017.

Moore, R.C., Teichert, C., and Cox, L.R., 1969, Treatise on invertebrate paleontology. Part N, Volume 1 (of 3) Mollusca 6 : Bivalvia: Boulder, CO, Geological Society of America ;

Morton, B., 1996, The Evolutionary History of the Bivalvia, in Origin and evolutionary radiation of the Mollusca, Oxford; New York, Oxford University Press, p. 337-359.

Nürnberg, S., and Aberhan, M., 2013, Habitat breadth and geographic range predict diversity dynamics in marine Mesozoic bivalves: Paleobiology, v. 39, p. 360-372, doi:10.1666/12047.

Raup, D.M., 1985, Mathematical Models of Cladogenesis: Paleobiology, v. 11, p. 42-52.

Rominger, A.J., Fuentes, M.A., and Marquet, P.A., 2019, Nonequilibrium evolution of volatility in origination and extinction explains fat-tailed fluctuations in Phanerozoic biodiversity: Science Advances, v. 5, p. eaat0122, doi:10.1126/sciadv.aat0122.

Roy, K., Jablonski, D., and Valentine, J.W., 2000, Dissecting latitudinal diversity gradients: functional groups and clades of marine bivalves.: Proceedings of the Royal Society B: Biological Sciences, v. 267, p. 293-299.

Runnegar, B., 1974, Evolutionary History of the Bivalve Subclass Anomalodesmata: Journal of Paleontology, v. 48, p. 904-939.

Stanley, S.M., 2015, Evolutionary Ecology of the Bivalvia, in Selden, P.A. ed., Treatise Online no. 72: Part N, Revised, Volume 1, Chapter 19, Paleontological Institute, The University of Kansas, p. 148, https://journals.ku.edu/treatiseonline/article/view/5055.

Stanley, S.M., 1990, The General Correlation Between Rate of Speciation and Rate of Extinction: Fortuitous Causal Linkages, in Causes of Evolution: A Paleontological Perspective, University of Chicago Press, p. 103-127.

Taylor, J.D. (Ed.), 1996, Origin and evolutionary radiation of the Mollusca: Oxford ; New York, Oxford University Press, 392 p.

Valentine, J.W., Jablonski, D., Kidwell, S., and Roy, K., 2006, Assessing the fidelity of the fossil record by using marine bivalves: Proceedings of the National Academy of Sciences, v. 103, p. 65996604, doi:10.1073/pnas.0601264103. 
Vermeij, G.J., 1977, The Mesozoic Marine Revolution: Evidence from Snails, Predators and Grazers: Paleobiology, v. 3, p. 245-258.

Vrba, E.S., and Gould, S.J., 1986, The Hierarchical Expansion of Sorting and Selection: Sorting and Selection Cannot Be Equated: Paleobiology, v. 12, p. 217-228.

Wake, D.B., and Vredenburg, V.T., 2008, Are we in the midst of the sixth mass extinction? A view from the world of amphibians: Proceedings of the National Academy of Sciences, v. 105, p. 1146611473, doi:10.1073/pnas.0801921105. 


\section{Appendix}

\section{Paleobiology Database Download Query}

http://paleobiodb.org/data1.2/occs/list.csv?datainfo\&rowcount\&base_name=Mytilidae,\%20Luci

nidae, $\% 20 \mathrm{Pectinidae}, \% 20 \mathrm{Pholadomyidae}, \% 20$ Veneridae\&taxon_reso=species\&idqual=certain\&

$\underline{\max \_\operatorname{ma}=251.9 \& \min \_m a=0 \& \text { show }=\text { class, } \text { classext,refattr,acconly }}$

\section{R Code}

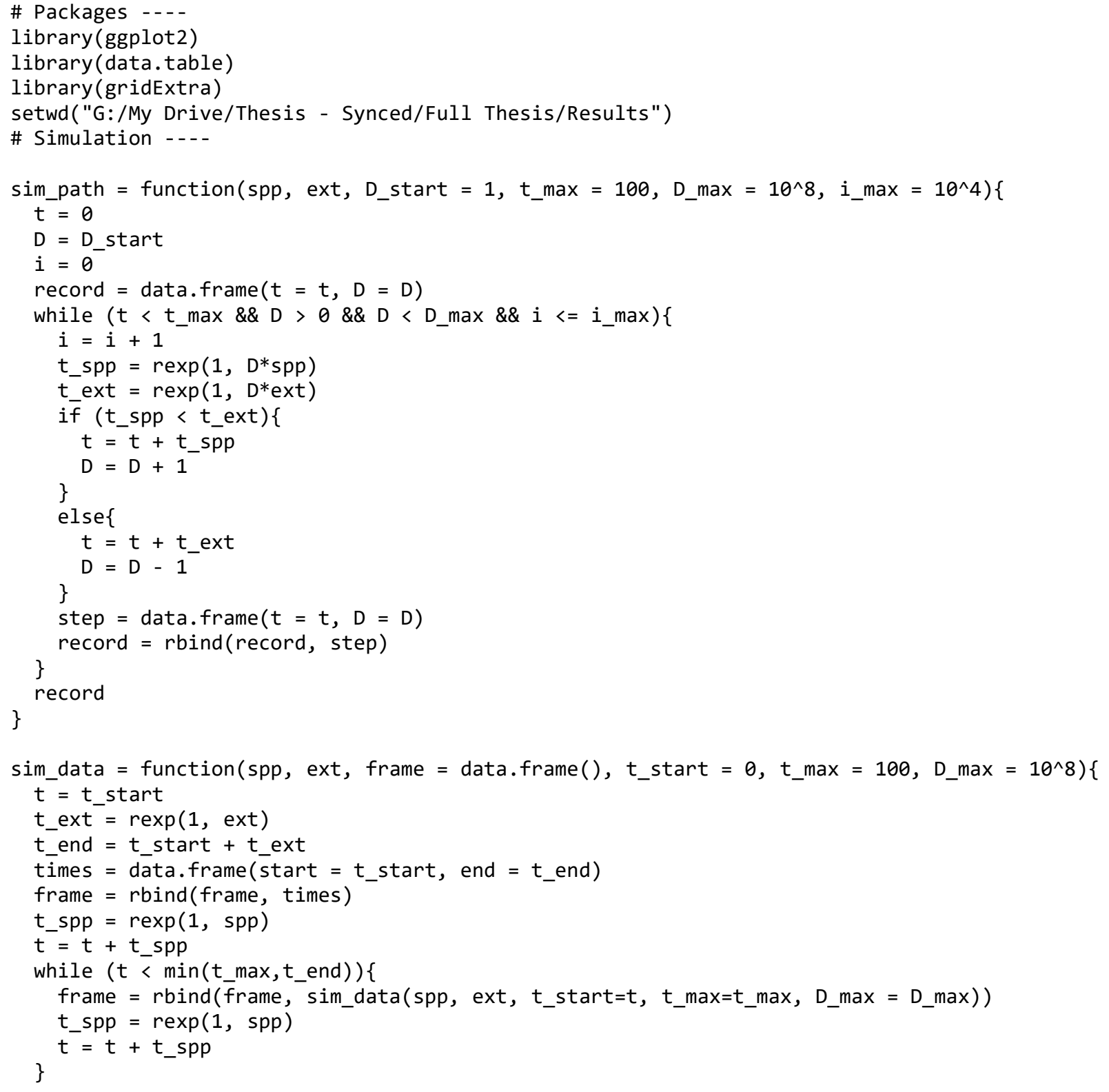




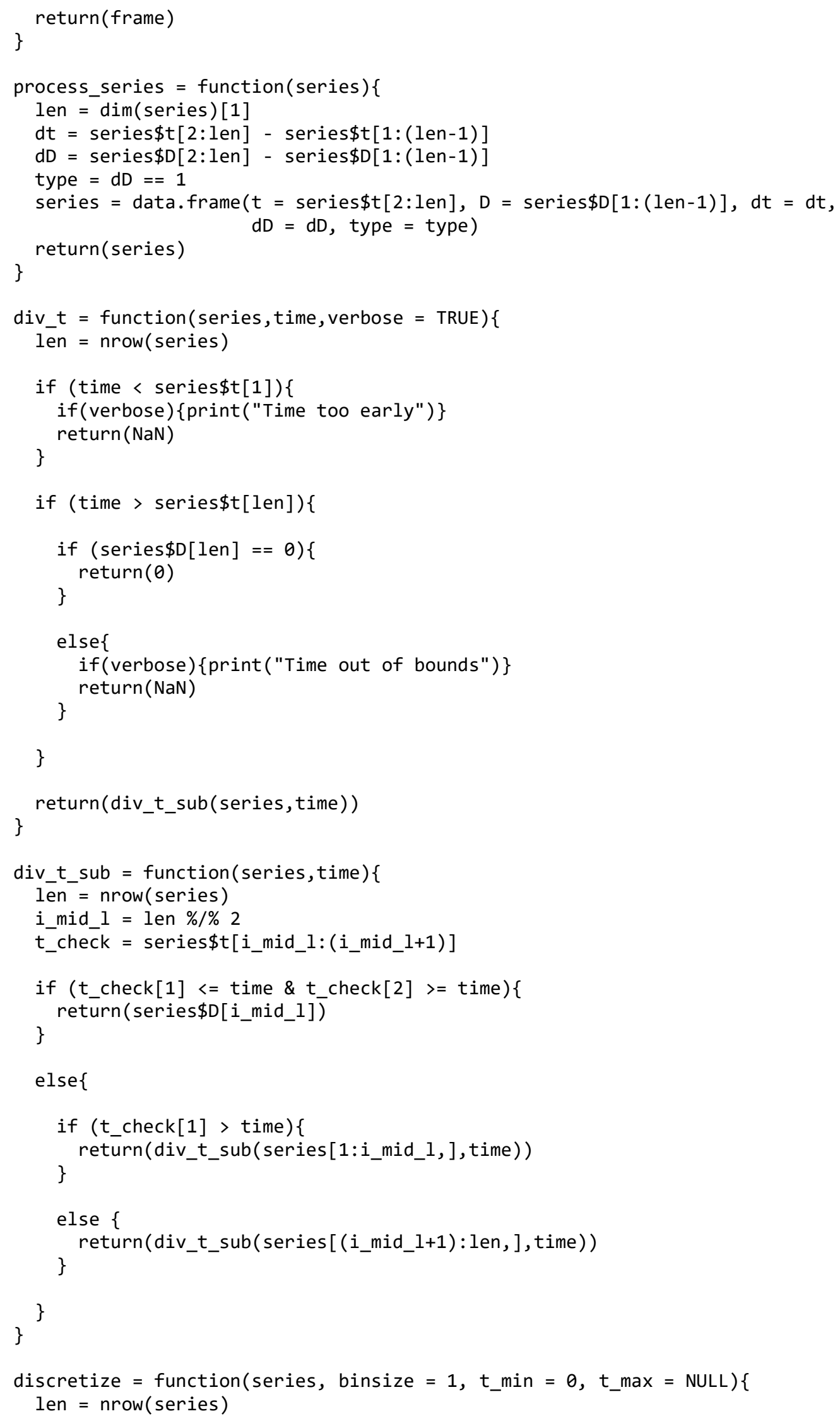




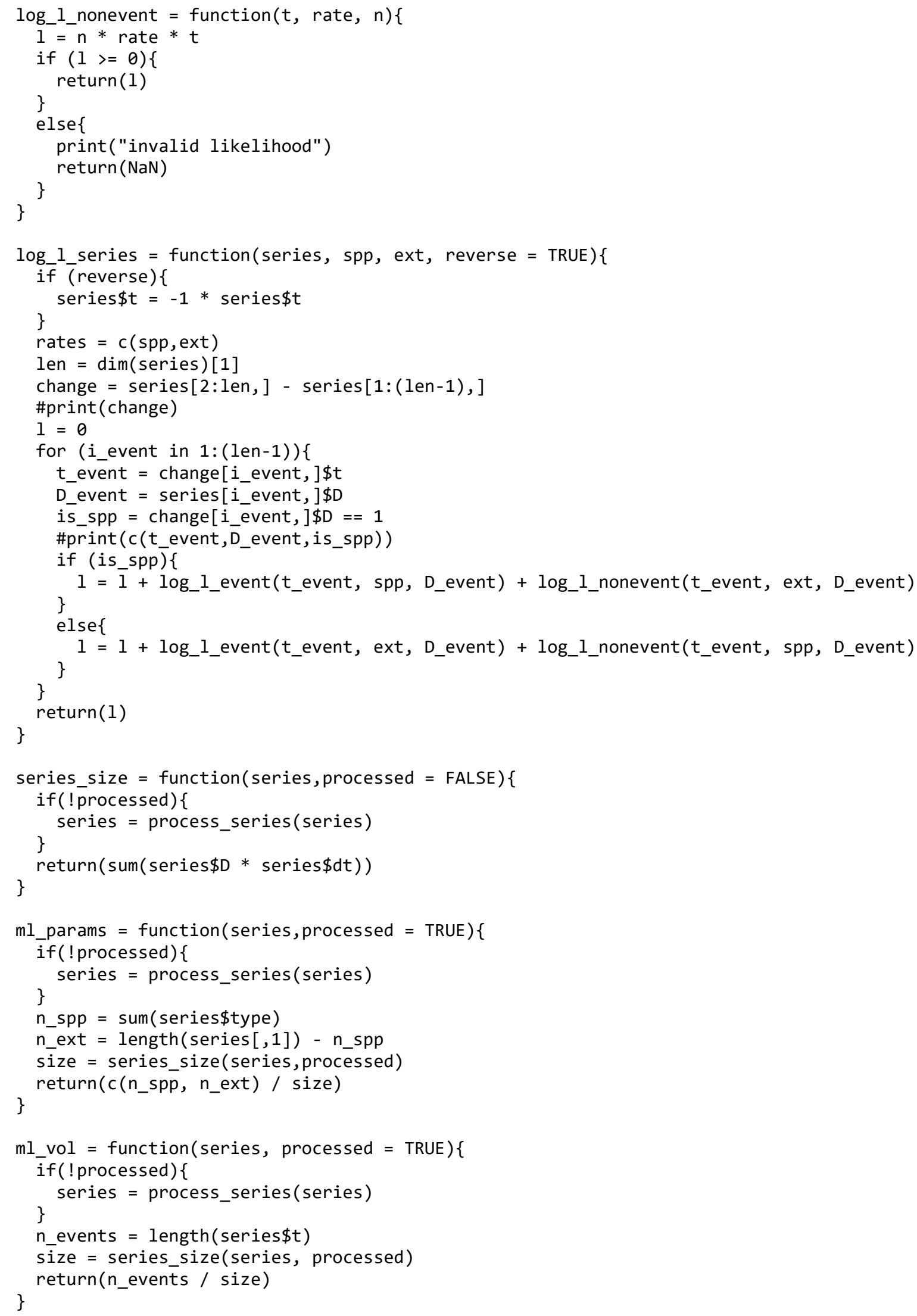




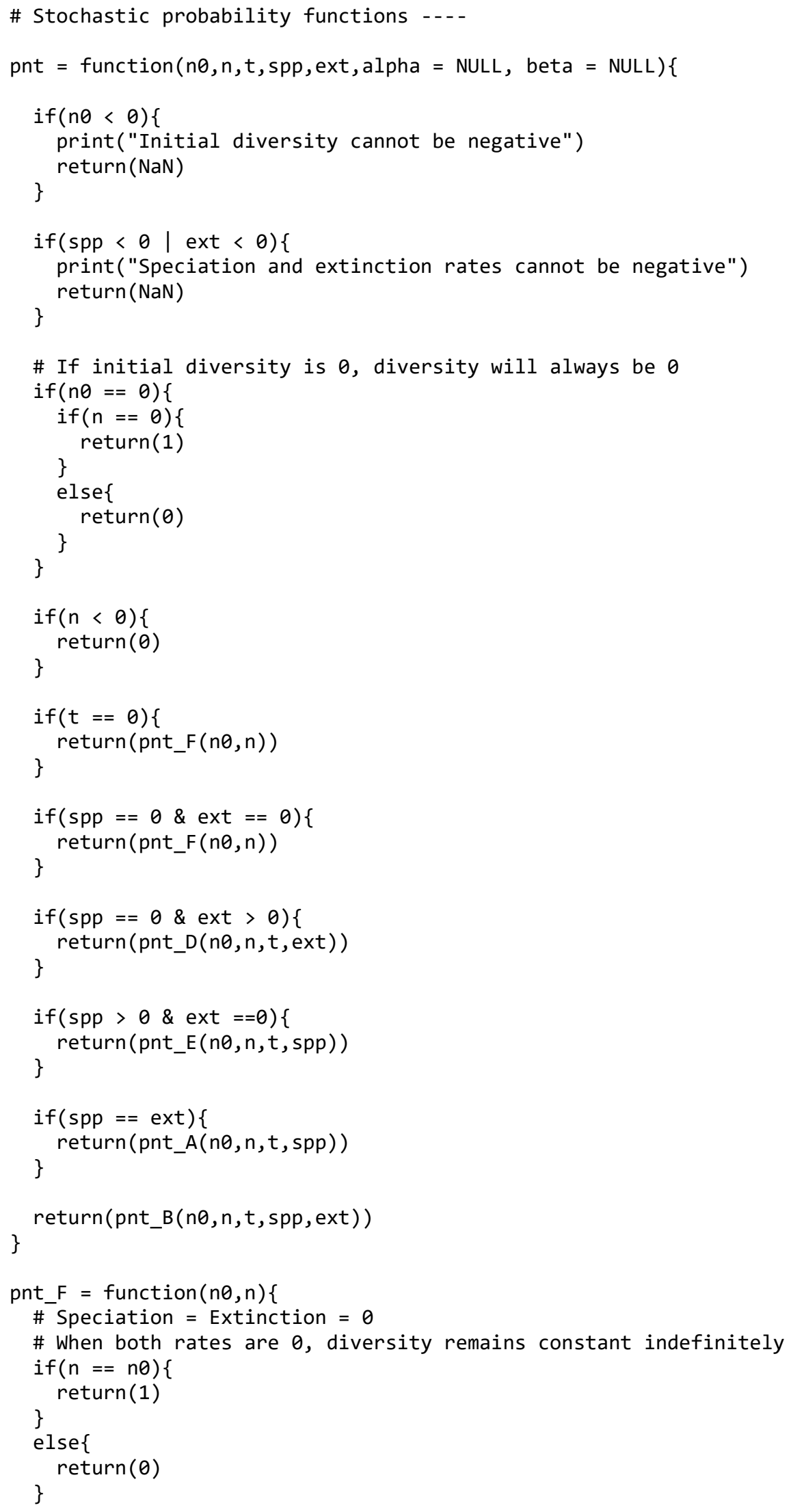




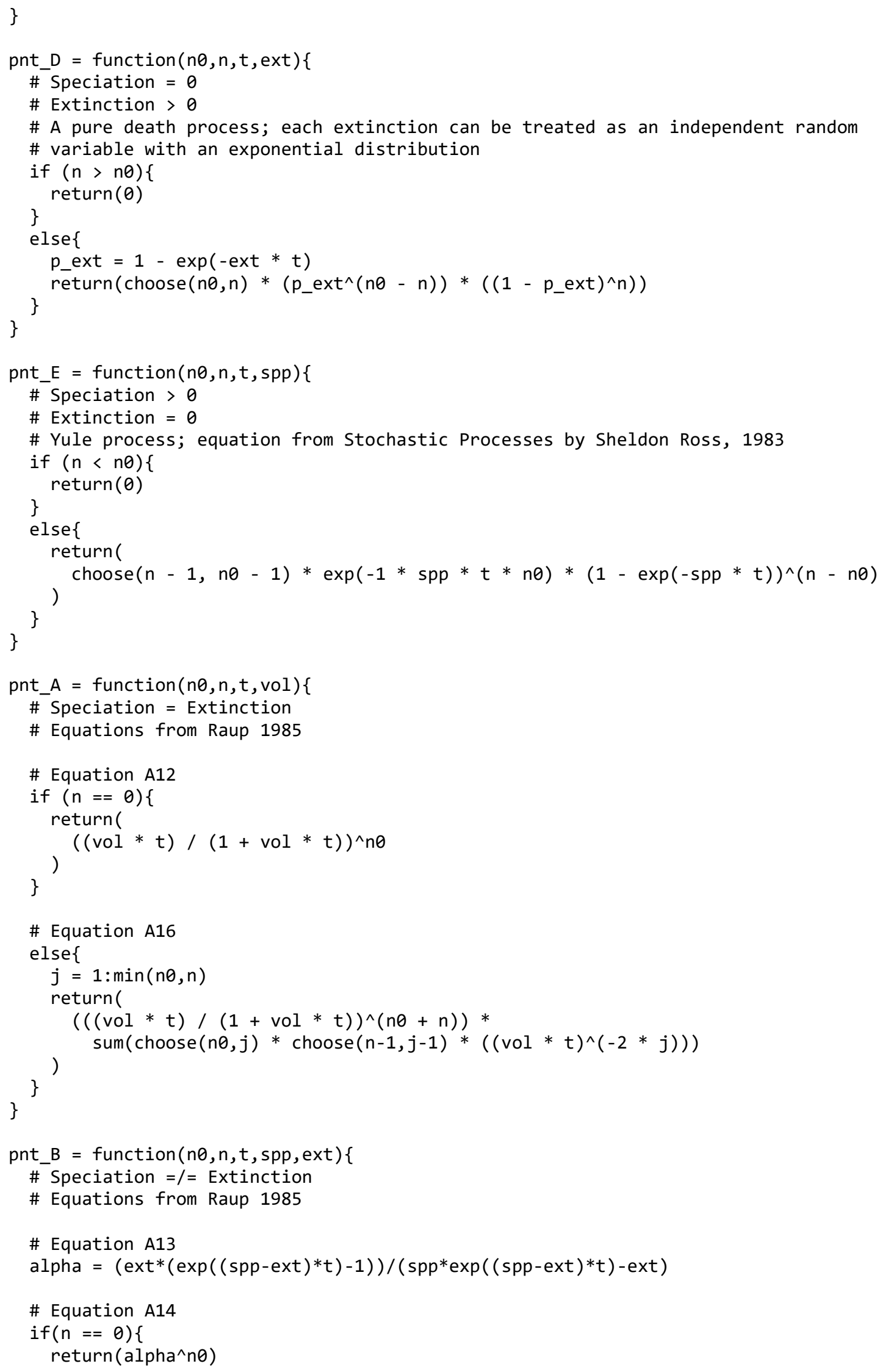




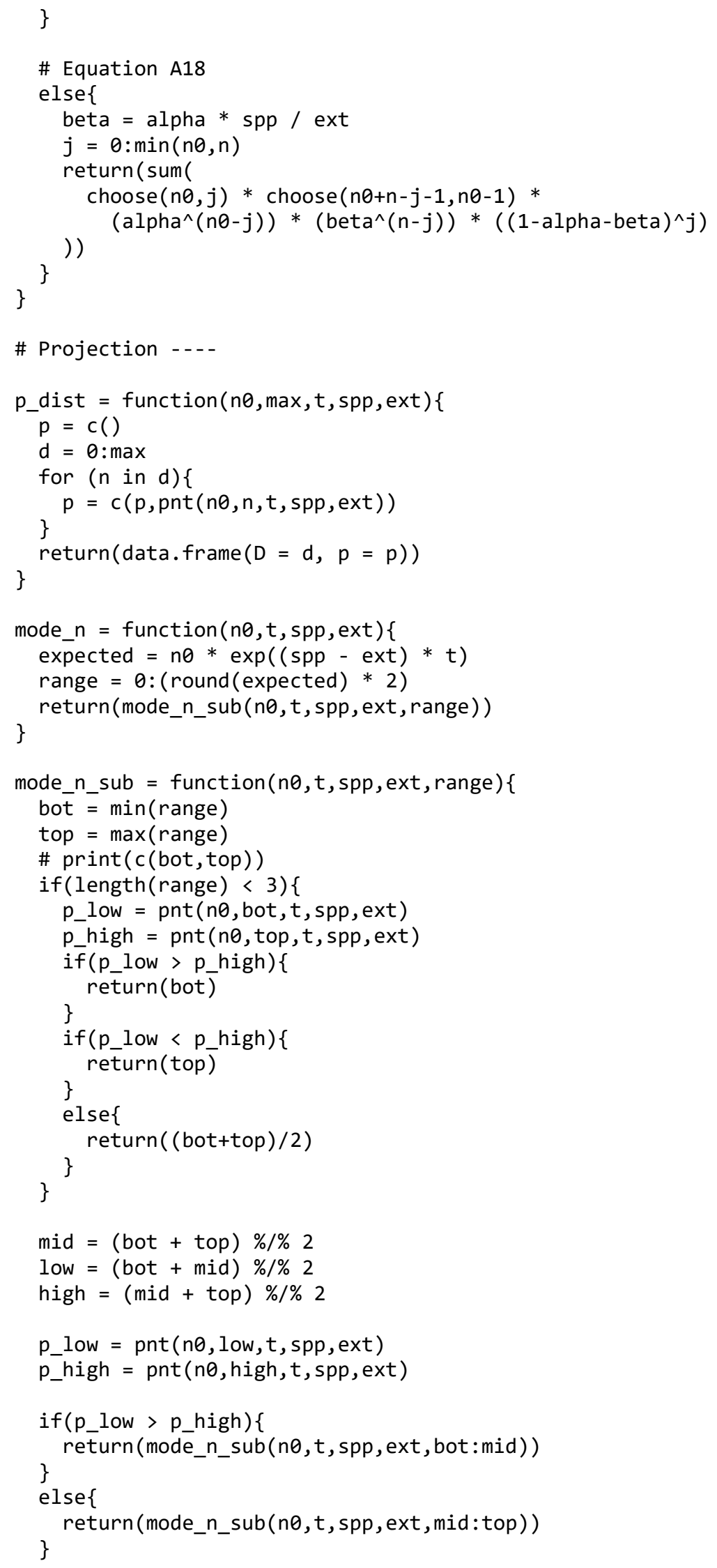




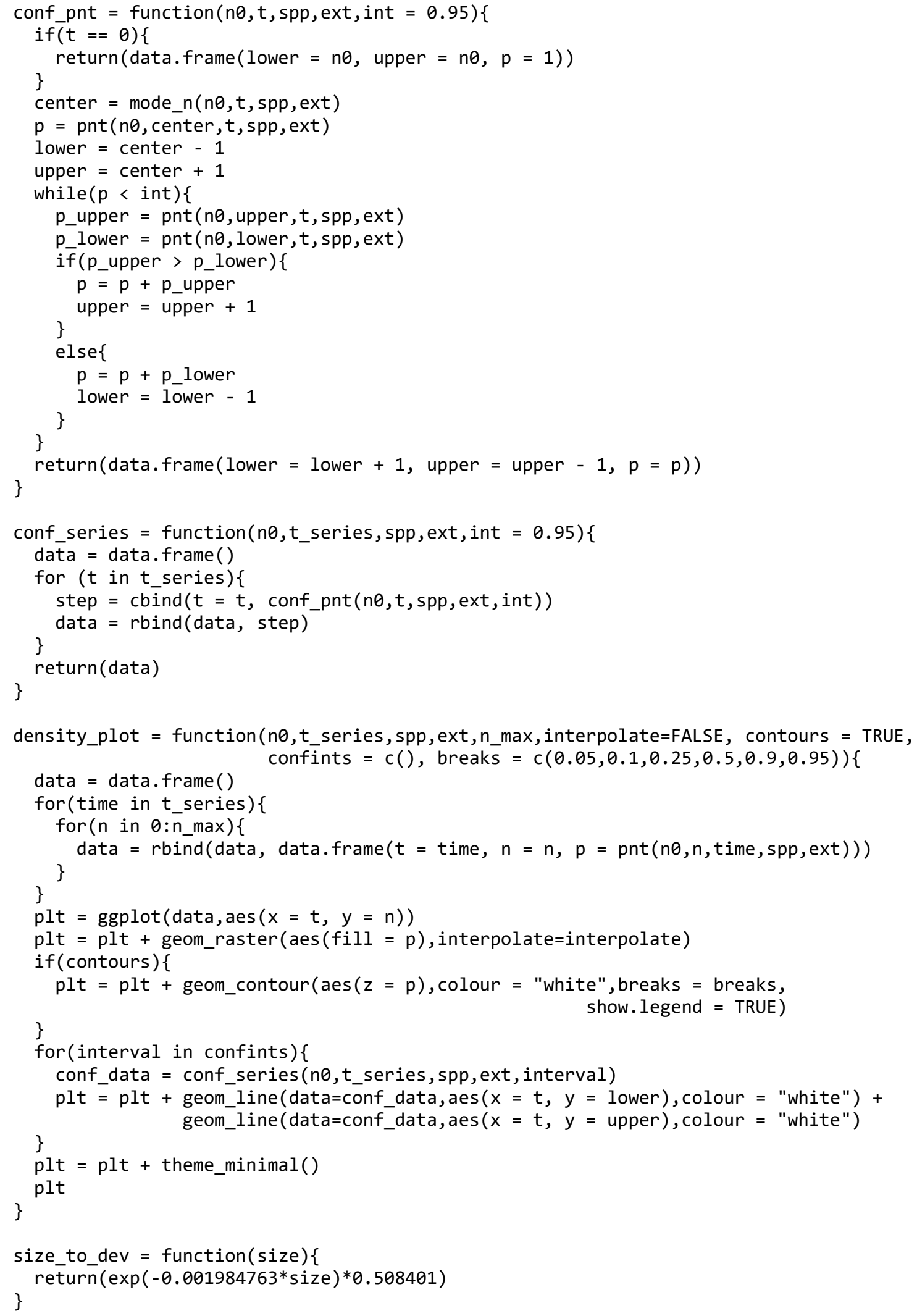




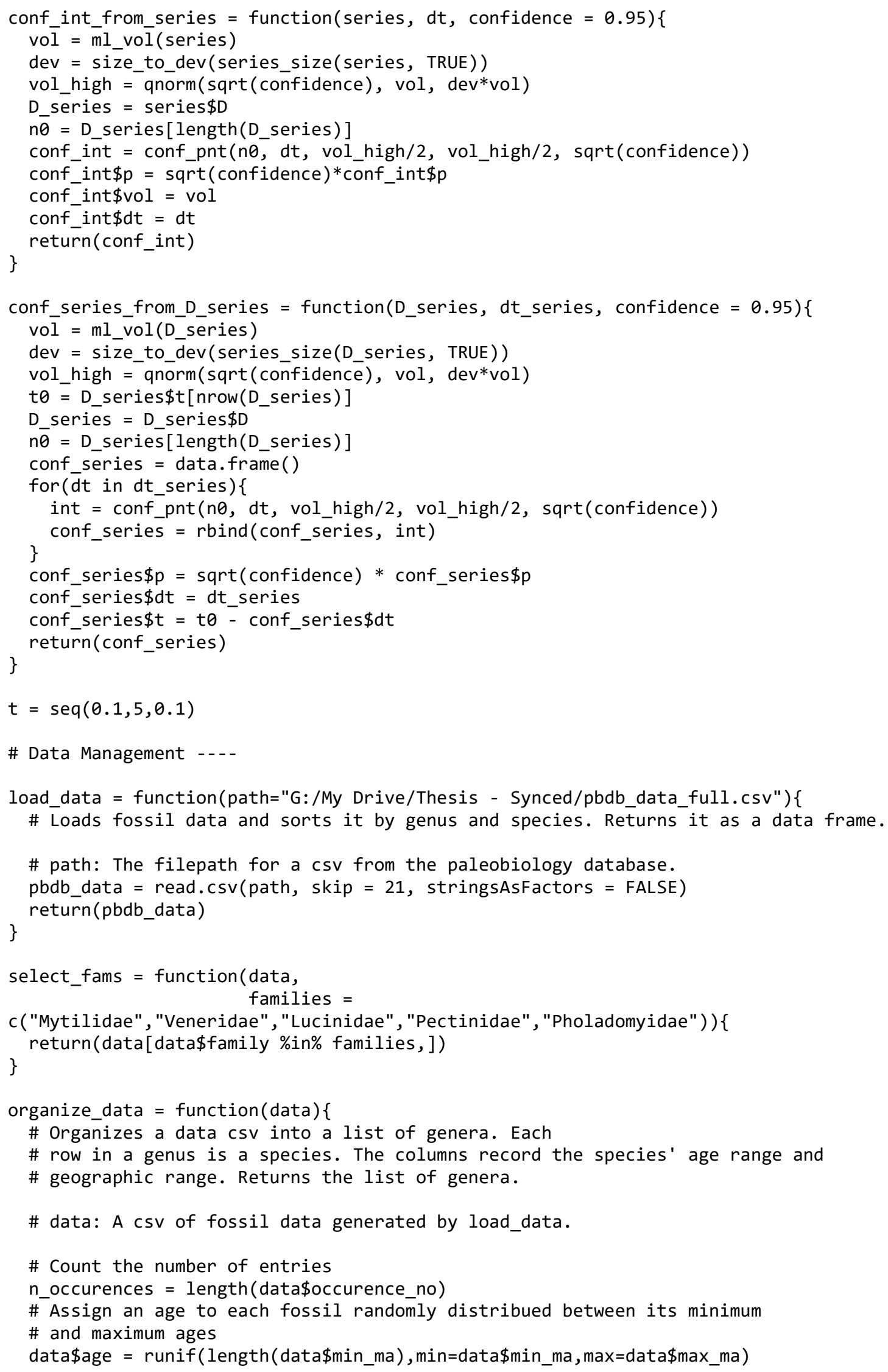




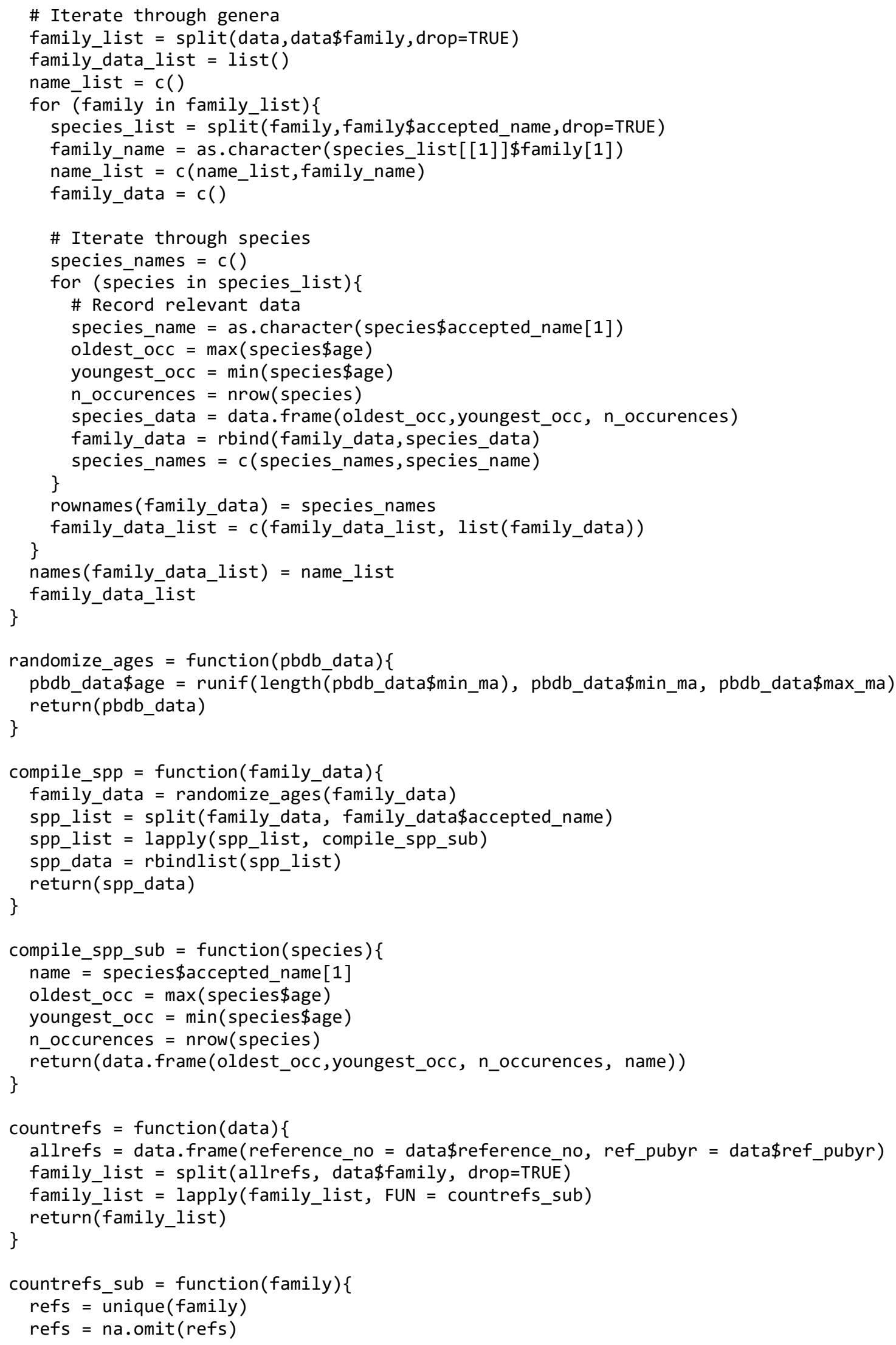




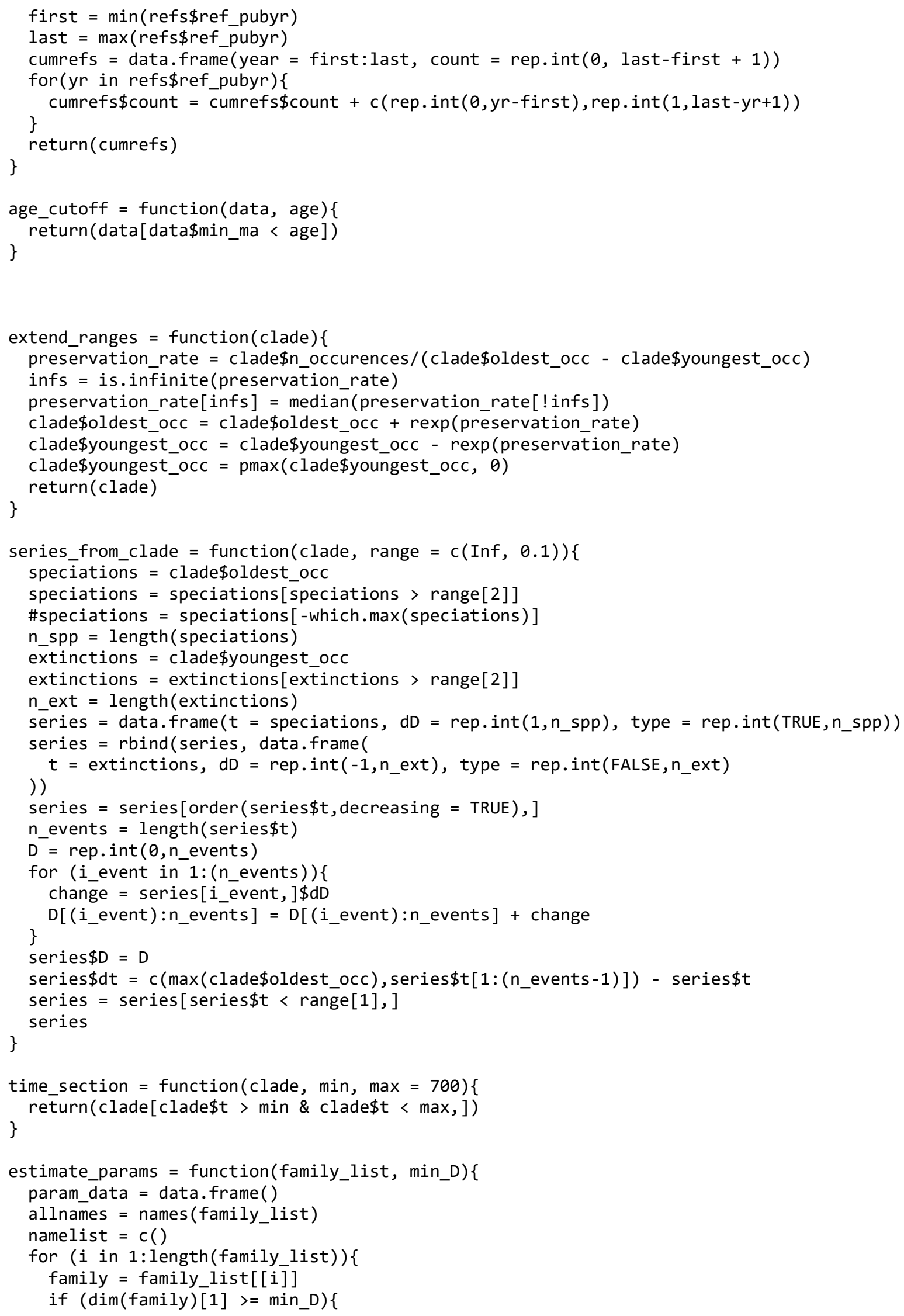




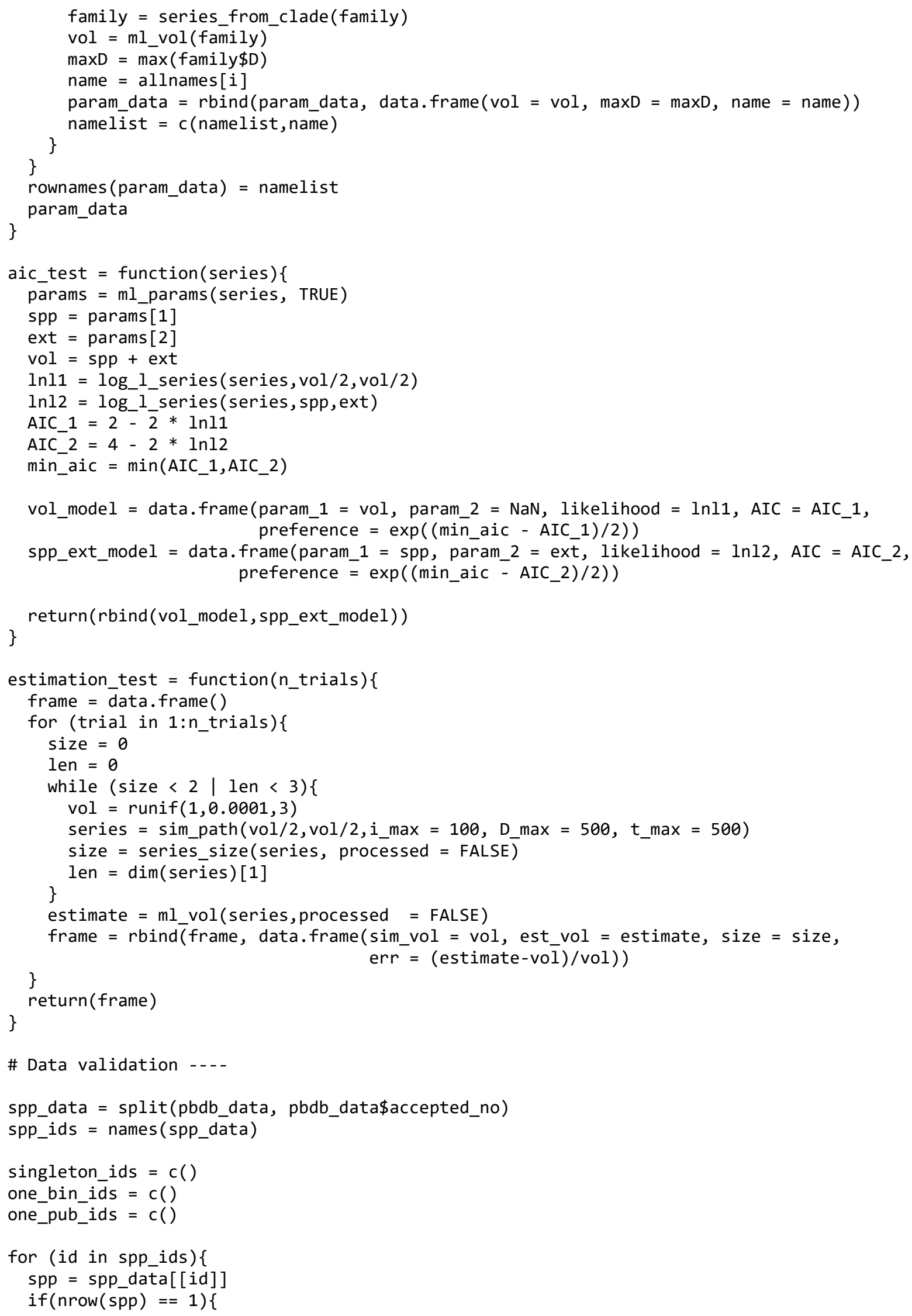









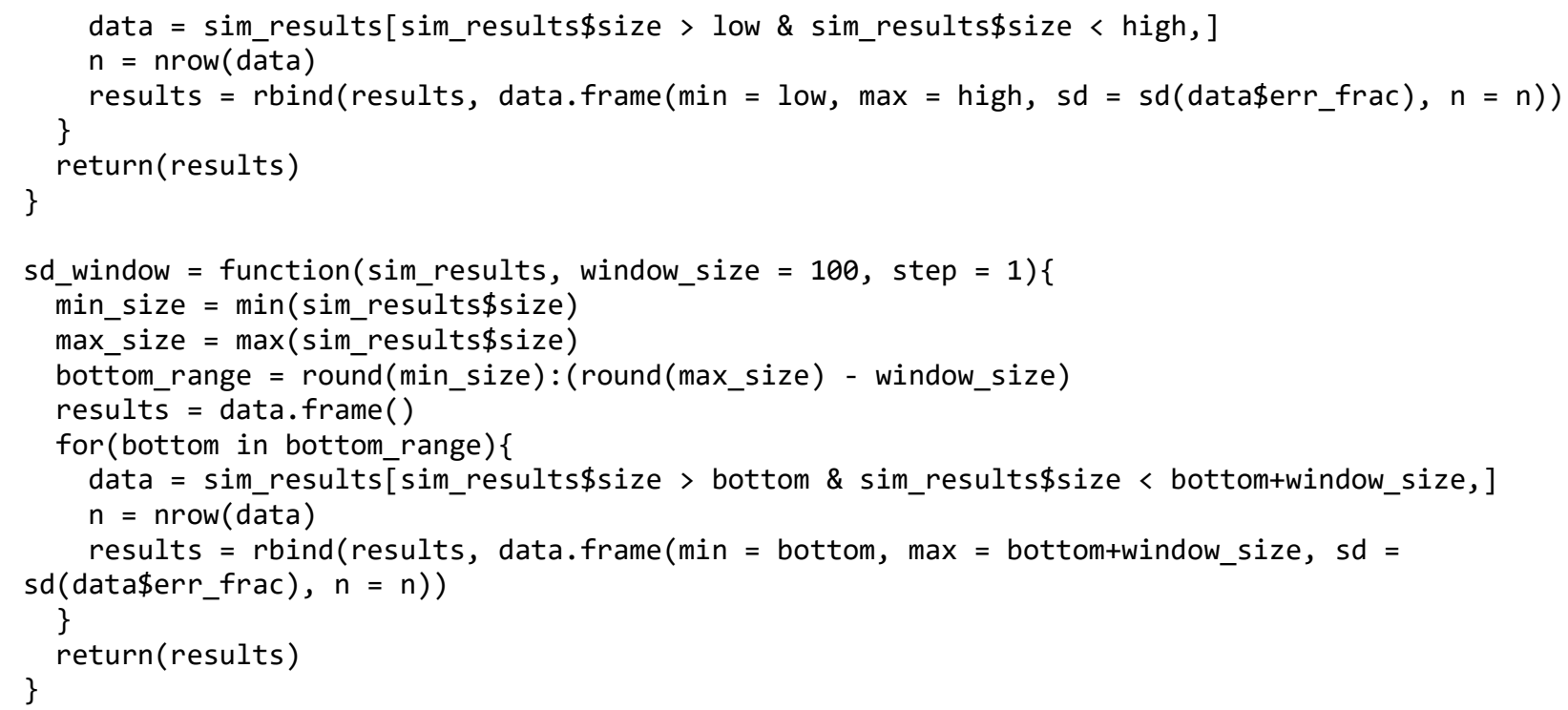




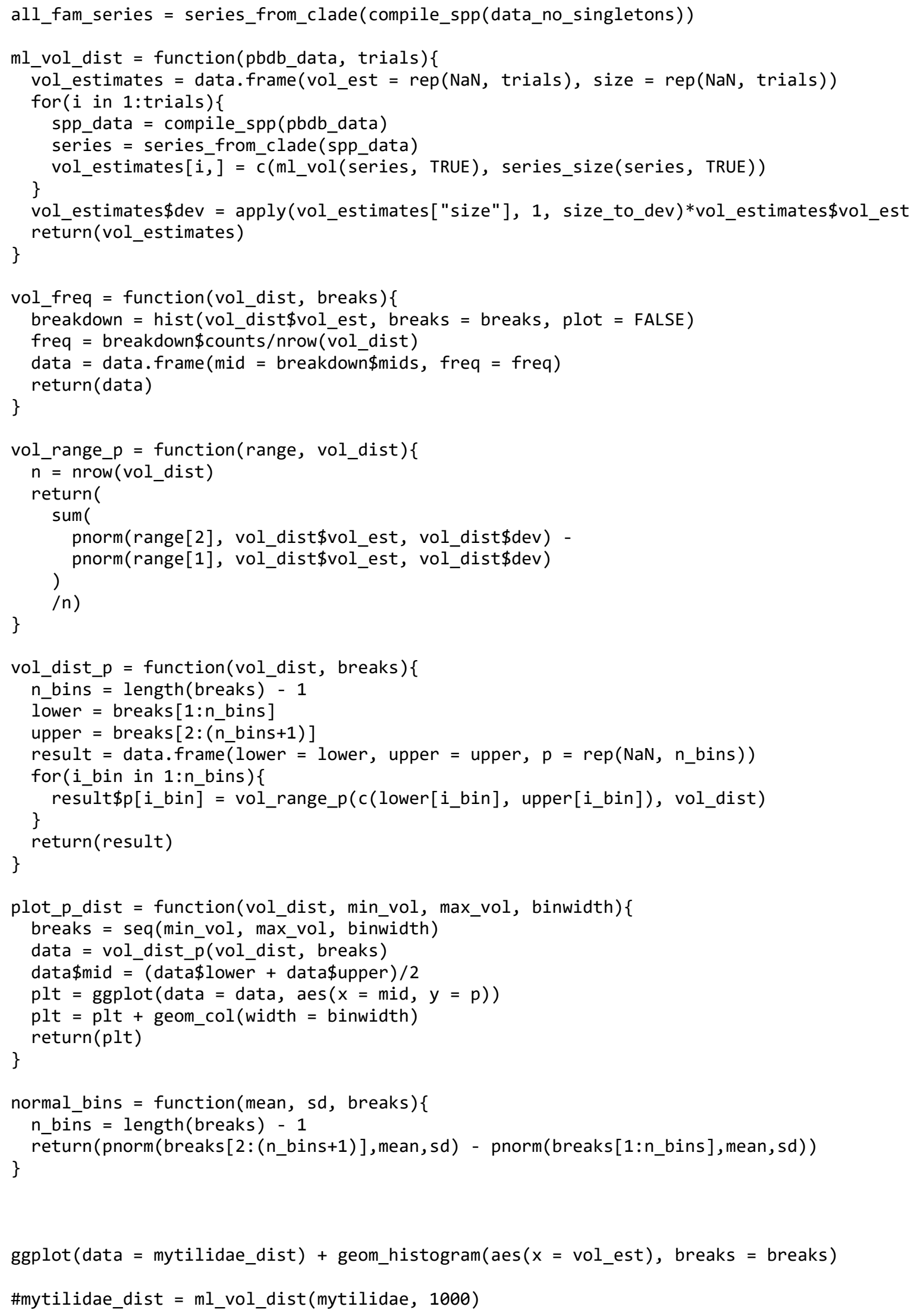




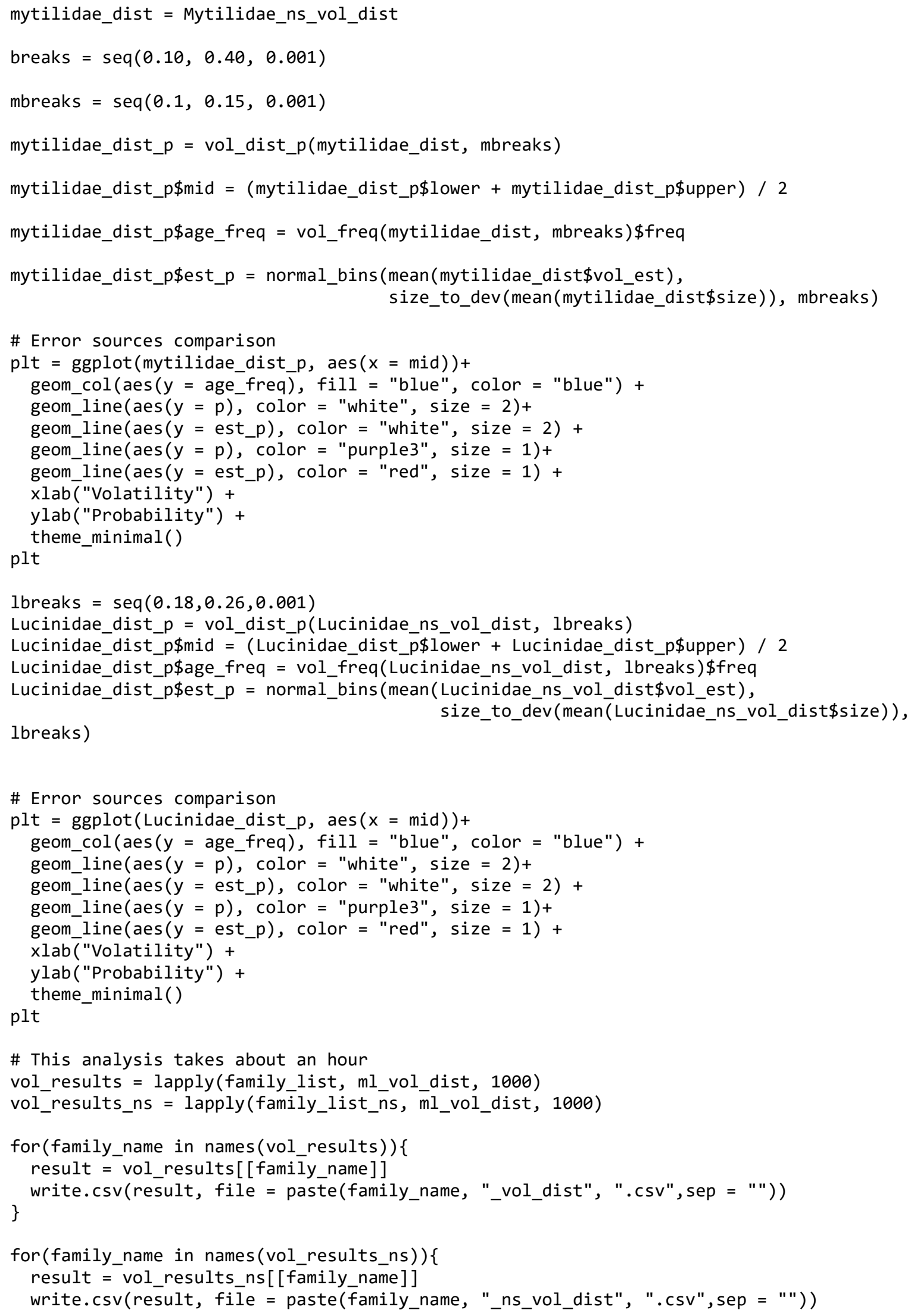


vol_dist_plot $=$ function (family_name, full_data, ns_data, breaks $=$ breaks, pmax $=0.27)\{$ plit $=\overline{g g p l o t}()$ 


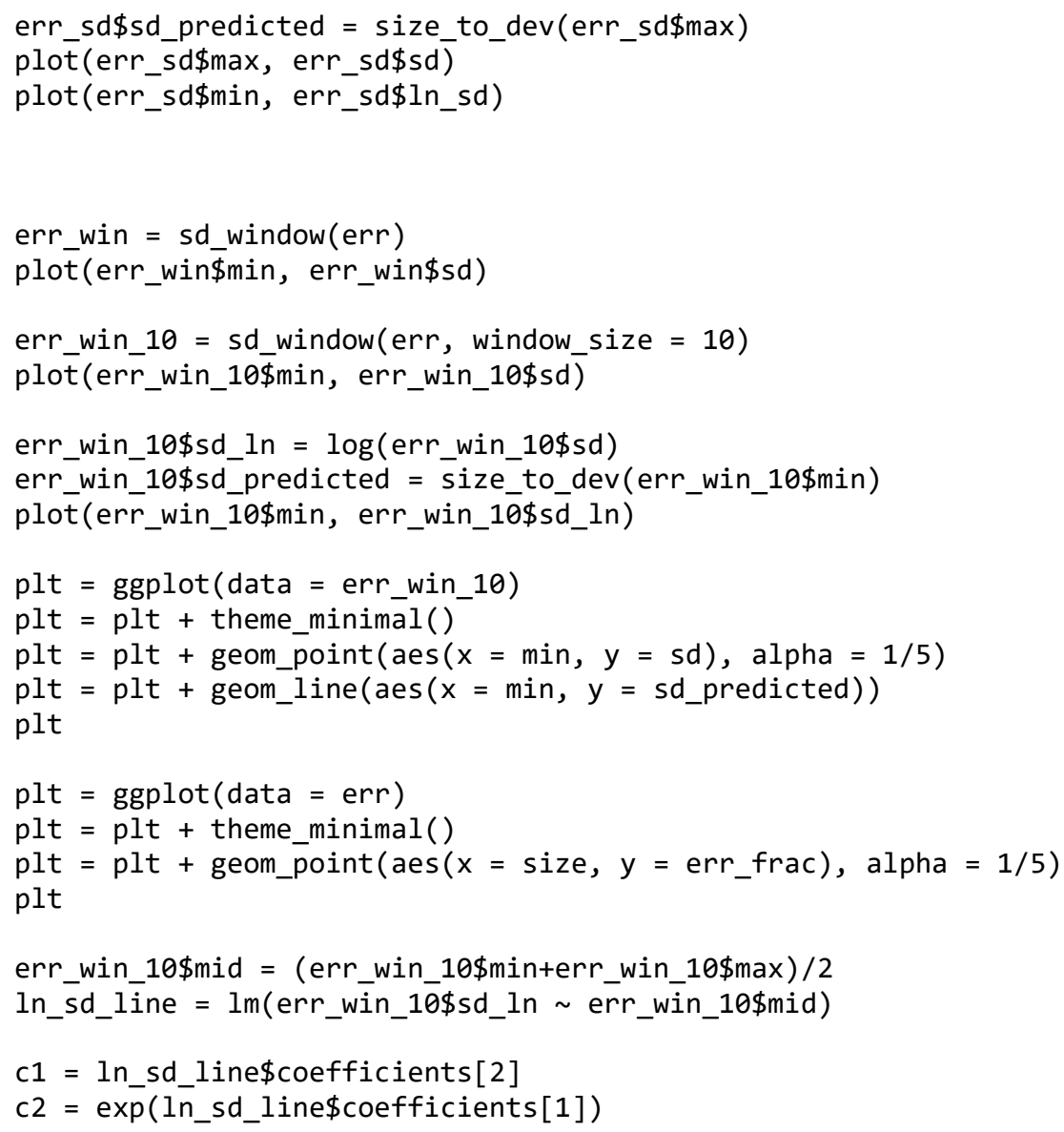

